\title{
LA SEMÁNTICA CONFUSA DE LA IGUALDAD *
}

\author{
Ricardo García Manrique \\ Universidad de Barcelona
}

RESUMEN. El recurso al valor de la igualdad en el discurso práctico es muy frecuente, pero quizá no es necesario ni conveniente y, en ese caso, deberíamos renunciar a él. En este trabajo intento mostrar que, al menos en el ámbito de las teorías de los derechos: 1) el recurso al valor de la igualdad no es necesario porque, cuando el término «igualdad» se usa para designar un valor, lo que designa, según los casos, es el valor que corresponde a la justicia o a la libertad, o bien ciertos hechos acerca de la naturaleza humana; es decir, la igualdad no posee un valor autónomo y distinto. También 2) que ese recurso no es conveniente porque da lugar a enunciados de significado confuso que dificultan el análisis correcto de los problemas normativos. En consecuencia, debemos evitar el uso valorativo del término «igualdad» o, si lo seguimos usando, ser conscientes de que no designa un valor distinto del de la justicia o el de la libertad. De este modo, las propuestas políticas igualitaristas, como la que expresan los derechos sociales, resultarán mejor articuladas y más atractivas.

Palabras clave: igualdad, justicia, libertad, derechos, valores, igualitarismo.

ABSTRACT. Appealing to the value of equality in practical discourse is frequent, but it is perhaps not necessary nor advisable; if this is the case, we should give up using it. In this essay I try to show that, at least within the sphere of rights theories: 1) the appeal to the value of equality is not necessary because, when the word "equality" is used to name a value, what it really names is the value of justice or the value of freedom or certain facts concerning human nature; i. e., equality does not hold any autonomous or distinct moral worth. Besides, 2) the appeal to equality is not advisable because it produces confusing statements that prevent from a correct analysis of normative problems. Consequently, we should avoid the evaluative use of the word "equality» or, if we keep on using it, be aware that it does not refer to a value different from that of justice or freedom. This way egalitarian political proposals, such as the one expressed by social rights, will be better formulated and more attractive.

Keywords: equality, justice, freedom, rights, values, egalitarianism.

* Fecha de recepción: 22 de marzo de 2011. Fecha de aceptación: 5 de abril de 2011. 


\section{EL DISCUTIBLE VALOR DE LA IGUALDAD}

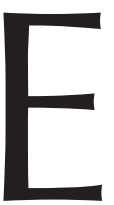

1 discurso moral, político y jurídico está plagado de referencias al valor de la igualdad o al valor de alguna de las varias igualdades en que parece ser que se descompone: igualdad ante la ley, igualdad formal, igualdad material o sustantiva, igualdad jurídica, igualdad de hecho, igualdad como equiparación, igualdad como diferenciación, etc. A menudo, el sentido de estas referencias no está nada claro, de manera que su proliferación da lugar a un empleo confuso del término: es difícil saber de qué hablamos cuando hablamos de igualdad. A primera vista, parece que la igualdad, considerada de forma unitaria o simple, expresa un valor distinto del de la justicia y del de la libertad (por ejemplo, así lo da a entender el art. 1 de la Constitución española); por otra parte, parece que la igualdad, cuando es cualificada de alguna manera, expresa valores distintos entre sí, de modo que el valor de la igualdad ante la ley y el de la igualdad material, el valor de la igualdad jurídica y el de la igualdad fáctica, parecen no ser uno y el mismo.

Sin embargo, un análisis más atento puede mostrar: 1) que el valor atribuido a la igualdad no es un valor autónomo y distinto, sino, según los casos, el que corresponde a la justicia y a la libertad, y 2) que los distintos valores expresados por las distintas igualdades son, también, los de la justicia y la libertad. Si esto puede mostrarse, quizá sería conveniente renunciar a emplear el término «igualdad» a la hora de justificar axiológicamente normas, derechos o acciones, y usar en su lugar los términos «justicia» o «libertad»; o, por lo menos, habría que tomar conciencia de que los enunciados que apelan a la igualdad en realidad están apelando a la justicia o a la libertad. De este modo, el lenguaje de la igualdad no se prestaría a tanta confusión como se presta: ganaríamos claridad y precisión, y estaríamos en mejor disposición para abordar algunos problemas clásicos de la filosofía política en los que la igualdad juega un papel, y entre los que destaca el conflicto que supuestamente la enfrenta con la libertad.

Con este fin, examinaré cuál es el lugar que corresponde al valor de la igualdad en un contexto concreto, el de las teorías de los derechos humanos o fundamentales, que son teorías fuertemente igualitarias, tanto si son teorías morales como si son teorías jurídicas. Las razones de la elección de este contexto son dos: una es ese componente igualitario que contienen estas teorías, del que se deduce que éste sería uno de los entornos del discurso práctico donde el valor de la igualdad habría de ser más relevante, si es que un valor tal pudiera ser afirmado; la otra es que me he interesado por la determinación del valor de la igualdad a la hora de reflexionar sobre el carácter fundamental de los derechos sociales; quizá merezca la pena hacer ver la conexión entre ambos asuntos, como forma de comprender la relevancia práctica de la indagación sobre el valor de la igualdad.

Sabido es que los derechos sociales suelen considerarse fundados en el valor de la igualdad y que el conflicto entre la libertad y la igualdad suele plantearse a la hora de determinar si tales derechos han de figurar en el catálogo de los derechos fundamentales y si lo han de hacer en el mismo plano o con la misma fuerza o relevancia que los demás. En general, la presentación dicotómica, dilemática o enfrentada de los valores de la igualdad y la libertad ha hecho pensar que cuando se sirve la causa de la libertad se perjudica la de la igualdad, y viceversa; o que una comunidad política más igualitaria es en 
algún sentido una comunidad política menos libre, y viceversa, porque ambos valores plantean exigencias distintas, divergentes y hasta contradictorias. Para la justificación de los derechos sociales, la dicotomía es nociva porque, en el mejor de los casos, hace creer que los derechos sociales están justificados porque sirven a la igualdad, pero en este caso son derechos que deben ser en alguna medida restringidos para que no perjudiquen en demasía la causa de la libertad, con lo que su número o su alcance habrá de reducirse. En el peor de los casos, se ha sostenido que los derechos fundamentales sirven sólo a la libertad y que, por tanto, los derechos sociales, dado que sirven a la igualdad, han de quedar fuera del ámbito de los derechos fundamentales. También cabe la posibilidad de que se afirme que libertad e igualdad son servidas conjuntamente por todos los derechos, pero esta afirmación, si es algo más que una obviedad, no ayuda mucho.

Yo creo que, en efecto, todos los derechos fundamentales sirven a la causa única de la libertad, pero que entre ellos se cuentan también los derechos sociales. La confirmación de esta creencia requiere, ante todo, dar razones de la conexión entre la libertad y los derechos sociales y, para ello, exige una reformulación o esclarecimiento del concepto de libertad. Sin embargo, el supuesto valor de la igualdad anda por medio y resultará muy útil, siendo posible, como creo que lo es, la tarea de descartar ese supuesto valor, despejando así el panorama axiológico que contemplamos. Para la correcta formulación de una teoría de los derechos fundamentales y para la ubicación de los derechos sociales dentro de ella, estoy convencido de que la errónea atribución de la categoría de valor a la igualdad resulta tan perturbadora como la comprensión inadecuada de la libertad. En cambio, una vez apartada la igualdad, habrá que convenir en que no sirve para identificar ni para justificar un tipo de derechos ni, por supuesto, cabe oponerla en modo alguno al valor de la libertad; sin embargo, la intuición a favor de los derechos sociales seguirá en pie y estaremos en mejor disposición para articularla racionalmente a través de su vinculación con la libertad, que podrá ser establecida con más precisión sin el concurso de la igualdad.

La conclusión a la que llegará el examen que propongo es que, en el ámbito de las teorías de los derechos, el uso del término «igualdad» remite o bien al valor de la justicia o bien al valor de la libertad o bien a ciertos hechos, de manera que es posible formular una teoría de este tipo sin apelar al valor de la igualdad, con lo que podemos renunciar a él tranquilamente. Aunque la conclusión se ciñe al ámbito de las teorías de los derechos, espero que sea útil también para los que se interesan por otros asuntos de la filosofía práctica ${ }^{1}$.

\section{EN EL NOMBRE DEL IGUALITARISMO}

Para evitar equívocos, importa reiterar el sentido de esta tarea. El nombre de la igualdad ha servido, y sirve, para designar causas de lo más noble. Bajo su bandera

${ }^{1}$ Por supuesto, no soy el primero en intentar el descarte de la autonomía o especificidad del valor de la igualdad. Cabe recordar los trabajos de BoBBIO, 1993: 56-61; RAZ, 1986: 217-244, o GuiBOuRG, 1996. La lectura de cualquiera de ellos, sobre todo del de BOBBIO, debería servir para los mismos fines que se buscan aquí. Son también muy útiles para esta causa los trabajos de P. WeSTEN (WESTEN, 1982 y 1990), aunque, en realidad, son un análisis de la idea que en este artículo llamaré «justicia». Acaso la particularidad de mi enfoque radica en que está orientado a la fundamentación de los derechos sociales. 
se han librado, y se libran, batallas que dignifican la historia política y social. Ninguna de esas causas y de esas batallas está aquí en cuestión, sino sólo si el valor de la igualdad es el más adecuado para identificarlas y promoverlas. Por eso, no hay que temer que la renuncia al supuesto valor de la igualdad en modo alguno deje abierta la puerta a la justificación de una sociedad más desigualitaria. Nada más lejos de la realidad, porque, si no yerro, es justamente al contrario: en lo que atañe a los derechos sociales, su fundamento no se verá debilitado, sino fortalecido, porque no requieren más justificación normativa que la que aporta el valor de la libertad, y esta justificación es mucho más fuerte y consistente que la que puede obtenerse a partir de la igualdad.

Tampoco el igualitarismo, concebido como cierto credo político, o como cierto rasgo típico de algunos credos políticos, ha de apoyarse en el valor de la igualdad, sino en el de la justicia, en el de la libertad, y en el reconocimiento de una cierta manera de ser común a todos los seres humanos. Creo que cualquier principio moral, político o jurídico que se exprese mediante el recurso a la igualdad puede expresarse también, y con más claridad y precisión, mediante el recurso a la justicia y la libertad. Por tanto, no se trata de que las exigencias normativas que se arropan con el manto de la igualdad sean ilegítimas o vacuas, sino, más bien, de que esas exigencias deben vestirse con otro traje más apropiado. No sé si estas pocas palabras bastarán para limar las reticencias que a menudo suscita quien se dispone a cuestionar el valor de la igualdad. Si no bastan, espero que sean vencidas por la fuerza de los argumentos que siguen y, en última instancia, por el hecho de que no es difícil extraer consecuencias netamente igualitarias de la conclusión a la que llega este ensayo. Por eso, podemos decir, con aparente paradoja, que la puesta en cuestión del valor de la igualdad debe hacerse en el nombre y por la causa del igualitarismo.

Con este fin, propongo un análisis en tres pasos. Primero, examinaré tres apariciones típicas de la igualdad en las teorías de los derechos para mostrar que ninguna de ellas requiere una consideración axiológica autónoma de la misma; segundo, me detendré en la igualdad ante la ley; y, tercero, en la igualdad material (de oportunidades, de bienestar o de recursos), en uno y otro caso con la intención de hacer ver que ninguna de ellas expresa tampoco valor intrínseco o específico alguno y que no necesitamos recurrir a ninguna de ellas para fundamentar nuestros juicios morales, nuestras creencias políticas o nuestra práctica jurídica.

\section{TRES APARICIONES DE LA IGUALDAD EN TODA TEORÍA DE LOS DERECHOS}

Supongamos que alguien se dispone a formular una teoría de los derechos fundamentales que deben atribuirse a las personas. Quien formula una teoría de este tipo asume tres premisas en las que la igualdad está presente, y que son:

1. Que se trata de una teoría normativa, es decir, de una teoría que contiene normas.

2. Que se trata de una teoría de la justicia.

3. Que los seres humanos son básicamente iguales en ciertos aspectos relevantes. 
En efecto, cada una de las tres premisas incluye una referencia a la igualdad y, por tanto, una teoría de los derechos es igualitaria en al menos tres sentidos: porque es una teoría normativa, porque es una teoría de la justicia y porque se basa en la creencia en cierta igualdad entre los seres humanos. A las tres igualdades presentes en las tres premisas podemos calificarlas como lógica, axiológica y fáctica.

\subsection{Igualdad lógica}

La igualdad contenida en la primera premisa aparece como un elemento lógico de la idea de norma. Toda norma es un esquema de calificación de la realidad que permite tratar conjuntamente una serie de casos, a partir de la extracción de todos ellos de un rasgo común, que es el que autoriza a calificarlos como iguales ${ }^{2}$. Toda norma, en este sentido trivial, es igualitaria, porque permite calificar como iguales a ciertos casos; es decir, una norma es igualitaria porque es, en alguna medida, general. Cuestión distinta es que el rasgo o propiedad común a todos los casos que es tomado en consideración por la norma no sea relevante, es decir, no venga a cuento, porque no consideremos oportuna su vinculación con la consecuencia de la norma. Por ejemplo: si una norma dictamina que «serán aprobados todos los alumnos que se sientan en la primera fila», es obvio que esta norma contempla una categoría de sujetos iguales (igualmente sentados en primera fila), pero bien puede creerse que esta igualdad es irrelevante al efecto de aprobar, quizá porque estar sentado en primera fila no constituye mérito alguno que haya de asociarse con aprobar o no. Los alumnos sentados en primera fila son, de hecho, iguales en ese aspecto (el de estar ahí sentados) y, por obra y gracia de la norma, son también normativamente iguales, en el sentido de que a todos ellos se les atribuye la misma consecuencia, la de aprobar. La norma en cuestión puede ser calificada como injusta, por considerar relevante una propiedad que no lo es, pero lo cierto es que toda norma, injusta o no, es igualitaria, en cuanto que obliga a tratar igual los casos que son considerados iguales, es decir, a atribuir la misma consecuencia a todos los casos englobados por el supuesto fáctico. Sin embargo, esta igualdad no dota de valor alguno a las normas, como lo muestra el ejemplo, que es el de una norma injusta y, por eso, no valiosa. Una teoría de los derechos es igualitaria, en este primer sentido, porque está compuesta por normas, pero esta igualdad es moralmente irrelevante. No necesitamos aquí atribuir a la igualdad el estatuto de valor, sino solamente comprender lo que es una norma.

Cabe repetir que, salvo las normas individuales (una categoría problemática que no tendré en cuenta aquí porque el argumento no lo requiere), toda norma ha de tomar en consideración a categorías de sujetos u objetos iguales en algo. Uno debe distinguir entre el hecho de esta igualdad y la relevancia o irrelevancia de la misma en relación con la consecuencia prevista por la norma. La norma, en función de esta relevancia, será justa o injusta, correcta o incorrecta, pero será siempre igualitaria en el sentido de que trata con grupos de iguales y porque les atribuye igual consecuencia.

Por la misma razón, cualquier actividad de aplicación de normas es una actividad igualitaria, ahora en el sentido de que requiere, lógicamente, tratar igual (y como la

\footnotetext{
2 Ross, 1997: 34-42.
} 
norma establece) los casos considerados iguales por esa norma. Por eso, al aplicar una norma estamos actuando igualitariamente, de nuevo con independencia de cuál sea el contenido de esa norma. Es cierto que algunos creen que aplicar consistentemente las normas, con independencia de cuál sea su contenido, es una actitud moralmente valiosa, y hacen radicar en la igualdad el valor de esta acción. Sin embargo, el valor que pueda haber en la acción de aplicación de normas es acaso el de la justicia, porque, en cierto sentido (al que se suele llamar «formal»), aplicar una norma siempre es justo, formalmente justo (en el sentido de que se tratan igual los tratos igualmente considerados por la norma). Con la misma intención, podemos hablar de «justicia legal», como ARISTÓTELES, de «justicia como regularidad», como RAWLS, o de «justicia en la aplicación del Derecho», como HART ${ }^{3}$. Incluso hay quienes, desde HOBBEs hasta Ross, consideran que ésta es la única justicia de la que se puede hablar ${ }^{4}$. En todo caso, si el valor que está en juego es el de la justicia, esto nos conduce al análisis de la siguiente premisa, en el que la igualdad se vincula con ella y no con la mera idea de norma.

\subsection{Igualdad axiológica}

En la segunda premisa, la igualdad vuelve a aparecer, ahora como elemento constitutivo o «médula» de la justicia ${ }^{5}$. Por lo menos desde ARISTÓTELES, la justicia es definida como el trato igual para los iguales y desigual para los desiguales ${ }^{6}$. Por eso, cuando actuamos justamente, actuamos también igualitariamente, de acuerdo con una regla de igualdad que nos permite determinar quiénes son iguales o desiguales para cierto efecto o consecuencia (el trato dispensado). Por tanto, toda norma justa es una norma igualitaria en este sentido, que, nótese, no corresponde con el anterior. Una norma es siempre igualitaria en el primer sentido, pero sólo es igualitaria en el segundo sentido cuando es justa. En cambio, una norma injusta es desigualitaria en este segundo sentido, porque no trata igualmente a los iguales o no trata desigualmente a los desiguales.

De este modo, y por exigencia de esta segunda premisa, toda teoría de los derechos es una teoría igualitaria porque es una teoría de la justicia. Esto no supone atribuir estatuto axiológico alguno a la igualdad, sino darlo por supuesto para la justicia, conceptualmente igualitaria por lo que vengo diciendo. Podemos hablar, en este caso, de una igualdad axiológica en el bien entendido de que el valor que ponderamos aquí es el de la justicia, puesto que el valor que no respeta la norma injusta no es el de la igualdad, sino el de la justicia, y conviene insistir en ello porque, a menudo, se acusa a una norma de desigualitaria cuando, en realidad, su vicio consiste en ser injusta. Esta desigualdad, que es moralmente rechazable porque genera injusticia, puede ser de dos tipos.

Según el primer tipo, la norma no atina con el criterio adecuado para determinar quiénes han de ser considerados iguales y quiénes desiguales a los efectos de la conse-

\footnotetext{
3 ARISTÓTELES, 1985: 1317b; RAWLS, 1973: 235; HART, 1980: 255.

${ }^{4}$ HiERRO, 2002: 14.

5 RADBRUCH, 1974: 31.

${ }^{6}$ ARISTÓTELES, 1985: 1131a, y 1997: 1280a.
} 
cuencia normativa, dando lugar a un trato desigual para los que deberían ser tratados igual. Así podía considerarse la punición del adulterio en el Código Penal español de 1944 (que exigía reiteración en el caso del varón pero no en el de la mujer), siempre que creamos que el género del adúltero no es relevante a los efectos de determinar los elementos del tipo penal (en contra de lo que parecía creer el legislador de la época). El varón y la mujer debían ser tratados igualmente y no lo eran; en este caso, la norma era desigualitaria, pero su defecto moral radicaba en la injusticia y no en la desigualdad como tal. Es fácil comprobarlo si tenemos en cuenta que, en otras ocasiones, ocurre lo contrario, es decir, que una norma que trata de manera desigual al varón y a la mujer es considerada justa, como muchos creen que es la Ley Orgánica 1/2004, de Medidas de Protección Integral contra la Violencia de Género, que en su Título IV modifica varios preceptos penales, imputando a ciertos delitos penas mayores para el varón que para la mujer. En este caso, el mérito moral de la norma, si en efecto lo tiene, no puede radicar en el trato igual sino en el trato desigual.

Según la desigualdad del segundo tipo, la norma acierta a la hora de determinar quiénes son iguales y desiguales a la hora de aplicarles una consecuencia, pero no lo hace a la hora de determinar la consecuencia. Es el caso de la norma que castiga el homicidio con la pena de muerte, si creemos que la pena de muerte no es merecida por los homicidas. En este caso, la norma es desigualitaria en dos sentidos: primero, porque trata desigualmente a los homicidas y a los que no lo son, pero esto lo consideramos justo; segundo, porque trata desproporcionadamente a los homicidas, sometiéndolos a una pena indebida, y por eso consideramos injusta a la norma. No es, por tanto, la desigualdad lo que convierte a la norma en moralmente incorrecta, sino la injusticia.

A menudo, cuando la igualdad es considerada como un valor, lo que se quiere decir precisamente es que el trato igual para los iguales y desigual para los desiguales es un valor, esto es, que la justicia es un valor. En estos casos, o bien los términos «justicia» e «igualdad» se usan como sinónimos o bien el término «igualdad» se usa para designar a lo que aquí hemos llamado «justicia» y el término «justicia» se usa para designar alguna otra cosa. El primer caso es el de WESTEN, que establece:

«Por "igualdad" entiendo la proposición en Derecho y en ética de que "la gente que es igual debe ser tratada igualmente" y su correlativa, que "la gente que es desigual sea tratada desigualmente"».

Y más adelante:

«"Justicia" significa "dar a cada persona lo suyo"» 7 .

Para acabar mostrando que igualdad y justicia, tal y como han sido definidas, son la misma cosa, algo con lo que es difícil discrepar. El segundo caso parece ser el de LAPORTA, para quien el principio de igualdad significa que:

«Los seres humanos, sean cuales sean sus rasgos comunes o distintivos, deben ser tratados como iguales».

Un principio que incluye, a su vez, «tanto a los de no discriminación como a los de tratamiento diferenciado por rasgos relevantes» (o sea, trato igual para lo igual y desigual para lo desigual). En cambio:

\footnotetext{
7 WESTEN, 1982: 539 y 556.
} 
«Yo prefiero utilizar la expresión "justicia” como un vocablo genérico que denota tanto ambos tipos de principios de igualdad como otros relacionados con la certeza (lo que se ha llamado "justicia natural") y con la libertad» ${ }^{8}$.

Es decir, se denomina «igualdad» a lo que aquí he llamado «justicia» y se reserva el término «justicia» para ese conjunto más amplio de principios que, junto con otros, incluye a la propia igualdad.

En ambos casos estamos ante una cuestión puramente terminológica, puesto que se trata de elegir entre dos nombres (justicia e igualdad) para designar un mismo valor, que podemos seguir describiendo como el que consiste en el trato igual para los iguales y el trato desigual para los desiguales. Si el valor que se atribuye a la igualdad es el que corresponde a este tipo de trato, no debe haber mayor problema en admitirlo. Puede haber razones a favor y en contra del uso de uno u otro término. Uno puede pensar, por ejemplo, que, teniendo en cuenta lo que suele entenderse hoy por «teoría de la justicia», parece recomendable no limitar el nombre de «justicia» al principio aristotélico, sino usarlo para un entramado más amplio y complejo de principios, y reservar el nombre de «igualdad» para el principio aristotélico. No estoy seguro de que ésta sea una buena opción, porque, a pesar de los muchos contenidos que hoy podemos encontrar bajo el nombre de «teoría de la justicia», quizá pueden seguir siendo comprendidos como una respuesta, todo lo compleja que se quiera, a las preguntas que necesitamos responder para saber quiénes son iguales y quiénes no lo son, en función de qué, y cómo han de ser tratados unos y otros, de manera que sería precisamente la idea de la justicia aristotélica, y no otra, la que unificaría todos esos contenidos.

Una muestra significativa de ello es la teoría de la justicia de RAWLS, cuyo declarado objeto es «la estructura básica de la sociedad o, más exactamente, la manera en que las principales instituciones sociales distribuyen derechos fundamentales y deberes y determinan la división de las ventajas derivadas de la cooperación social». El propio RAWLS considera que su enfoque concuerda con el tradicional, puesto que, explica, si bien ARISTÓTELES parece referirse a la justicia como a una propiedad de determinadas acciones, su definición «claramente presupone una justificación de lo que pertenece propiamente a una persona y de lo que le es debido», y esta justificación deriva con frecuencia de las instituciones sociales y de las expectativas que suscitan, es decir, del que constituye el objeto de su teoría. No es casualidad que su contenido principal esté compuesto por los dos principios de la justicia, que son, precisamente, un principio de igualdad y otro de desigualdad, replicando la estructura de la fórmula aristotélica 9 .

En cambio, hay ocasiones en que el valor de la igualdad, aunque siga relacionado con el de la justicia, es considerado distinto del de ésta, de manera que la cuestión no es aquí sólo terminológica y, por tanto, merece mayor atención. RUIZ MIGUEL, en referencia a la equiparación entre igualdad y justicia que establece WESTEN, objeta:

«No parece del todo exacta la afirmación de que "igualdad" es un término de significación tan proteica que, equivaliendo al de justicia en sus formulaciones prescriptivas, pueda incorporar tanto las relaciones de (justa) igualdad como las de (justa) desigualdad» ${ }^{10}$.

\footnotetext{
8 LAPORTA, 1985: 4 y 26.

9 RAWLS, 1973: 7, 10 y 14.

10 Ruiz Miguel, 2002: 691.
} 
La razón que ofrece para sustentar esta objeción es que no todas las relaciones de desigualdad justa pueden ser formuladas como relaciones igualitarias, y pone dos ejemplos: el de la tributación progresiva, que no se puede reconducir a la igualdad proporcional, y el del alcance del principio constitucional de igualdad ante la ley, que exige el trato igual para los iguales pero no el trato desigual para los desiguales. Lo que parece deducirse de aquí es que, si la objeción es correcta, el valor de la igualdad no es el mismo que el valor de la justicia. La relación entre uno y otro sería de inclusión: toda igualdad moralmente deseable (como la exigida por la igualdad ante la ley) sería una igualdad justa, pero habría normas justas (como las que establecen la tributación progresiva) que no serían igualitarias. Sin embargo, no creo que esta conclusión pueda llevar a afirmar el valor de la igualdad con independencia del valor de la justicia. La razón la encontramos en el mismo texto de Ruiz MiguEL, un poco antes, cuando observa que:

«Al contrario de términos como "bondad", "corrección" o "generosidad" (y podemos añadir "justicia"), el término "igualdad", incluso en su significado prescriptivo, no es intrínsecamente ponderativo, esto es, no es un término que por definición no pueda ser usado con connotaciones neutras o, incluso, desfavorables. Es cierto que habitualmente, por razones culturales, psicológicas e históricas, "igualdad" tiende a asumir una carga valorativa positiva, pero no es contradictorio afirmar que hay igualdades indeseables» ${ }^{11}$.

A continuación, RuIz Miguel explica que el fundamento de estas connotaciones desfavorables que puede tener la igualdad en ocasiones se debe al criterio de justicia de ARISTÓTELES, de acuerdo con el cual la igualdad y la desigualdad pueden ser justas o injustas, moralmente deseables o moralmente indeseables. Luego de aquí se sigue que no es la igualdad como tal la que convierte en moralmente deseable a una norma o a una acción, sino la justicia. Si el término «igualdad» no es intrínsecamente ponderativo es precisamente porque no designa un valor, como sí lo designan los términos «bondad», «generosidad» o «justicia», y por eso sí son intrínsecamente ponderativos.

La justicia, por tanto, puede dar cuenta de todas las igualdades moralmente deseables: todas las que lo son, lo son porque son igualdades justas. Sin embargo, si mantenemos la objeción avanzada por RuIz MigueL, la igualdad no podría dar cuenta de todo el rango de lo justo. Esto creo que no debe preocuparnos demasiado ahora porque el hecho de que la justicia requiera en ocasiones una desigualdad no susceptible de ser formulada como relación igualitaria no es un argumento a favor de la consideración axiológica de la igualdad sino, acaso, un argumento en contra de la opción por denominar «igualdad» a la justicia. Aunque no puedo considerarlo aquí con el detenimiento necesario, el ejemplo de la tributación progresiva pondría de relieve, en efecto, que no es conveniente llamar «igualdad» a la justicia, si damos por supuesto que se trata de un sistema justo de tributación y que no es igualitario en ningún sentido aceptable del término (cosa que cabe por lo menos discutir, pues hay quien sostiene que la progresividad es un tipo de igualdad proporcional, siendo el otro la proporcionalidad en sentido estricto) ${ }^{12}$. En cuanto al ejemplo del principio constitucional de igualdad ante la ley, que supuestamente exigiría trato igual para los iguales pero no trato desigual

11 Ruiz Miguel, 2002: 688

12 Díez-Picazo, 2005: 200. 
para los desiguales, creo que plantea una cuestión distinta, de la que me ocuparé en la sección cuarta, dedicada específicamente a ese principio.

Otra combinación distinta entre la igualdad y la justicia la encontramos en el que DWORKIN considera que es el primer y principal derecho de las personas, a saber, el derecho a igual consideración y respeto. Este derecho, o principio, parece el resultado de la suma de dos afirmaciones diferentes: una, que el primer y principal derecho de las personas es el derecho a ser tratados con justicia; y dos, que las personas son relevantemente iguales en tanto que poseedoras de ciertas cualidades que hay que suponer previamente identificadas, de manera que todas ellas merecen consideración y respeto iguales y no distintos (como sucedería si, en vez de personas, fuesen otra cosa). Veámoslo a partir de uno de los pasajes en que se contiene su afirmación y donde se expresan tales cualidades:

«El gobierno debe tratar a los gobernados con consideración, es decir, como seres humanos capaces de sufrimiento y frustración, y con respeto, es decir, como seres humanos capaces de formarse y de actuar en función de concepciones inteligentes acerca de cómo deben vivir sus vidas. El gobierno debe tratar a la gente no sólo con consideración y respeto, sino con igual consideración y respeto» ${ }^{13}$.

Y añadamos que, al comienzo de su libro dedicado específicamente a la igualdad, escribe que la igual consideración y respeto es una «precondición de la legitimidad política» ${ }^{14}$. ¿Qué pretende decir DwORKIN con todo esto? Entiendo que lo siguiente: si los seres humanos son fácticamente iguales para sufrir o frustrarse, para formarse y actuar en función de concepciones de la vida buena, entonces deben ser igualmente tratados, en el sentido de igualmente considerados y respetados. Y esto significa que, a la hora de actuar justamente (que es lo que se supone que debe hacer el gobierno con los gobernados), debemos empezar por tener en cuenta que los sujetos de la relación justa son todos los seres humanos, y no sólo algunos de ellos; pero esto no parece que añada nada a la suma resultante de afirmar: 1) el valor de la justicia, y 2) un cierto tipo de igualdad de hecho entre los seres humanos, es decir, las premisas igualitarias segunda y tercera de toda teoría de los derechos tal cual las enuncié al principio de esta sección. Por eso, la igual consideración y respeto es una «precondición de la legitimidad política», lo que, en cuanto atañe a lo normativo (a la justicia, no a la manera de ser de los humanos), no es más que decir que la disposición a actuar justamente (o a actuar de acuerdo con el correspondiente esquema de legitimidad política) es una precondición para actuar justamente, algo de lo que no podemos discrepar.

Por eso, también, DwORKIN puede sostener que «el derecho a igual consideración y respeto es más abstracto que las concepciones estándar de la igualdad que distinguen a diferentes teorías políticas» ${ }^{15}$; porque toda teoría política, si es una teoría de la legitimidad política, es una teoría de la justicia, y casi todas las teorías políticas contemporáneas (si es que no todas) asumen la radical igualdad de todos los seres humanos. En este carácter igualitario de todas las teorías políticas hace hincapié también SEN, aunque no acaba de explicar por qué, a salvo de la sola referencia a su carácter norma-

\footnotetext{
13 DwORKIN, 1978: 272-273.

14 DwORKIN, 2000: 2.

15 DwORKIN, 1978: 180.
} 
tivo; cabe pensar que hubiera podido añadir que se debe a las razones que acabo de apuntar, y no sólo, aunque también, al hecho de que se trate de teorías normativas ${ }^{16}$.

En consecuencia, no parece que cuando DwORKIN llama «virtud soberana» a la igualdad se refiera a otra virtud distinta de la de la justicia, esa a la que RAWLS llama «primera virtud» de las instituciones sociales ${ }^{17}$. Entendida como igual consideración y respeto de las personas, la igualdad no supone un valor distinto del que atribuimos a la justicia, sino que añade la simultánea constatación de la igualdad fáctica de todas las personas. Dado que esta constatación lo es de un hecho, debería separarse de la prescripción de la virtud o valor público soberano, que es una proposición normativa. No veo ventaja alguna en mezclar en una única afirmación un juicio de hecho y un juicio de valor cuando ambos pueden enunciarse con mayor claridad por separado, salvo que, como apunta RAZ, quizá se obtenga una fórmula más «atractiva», «retórica» o «a la moda», aunque, eso sí, al precio de la «confusión intelectual» ${ }^{18}$.

Uno de esos atractivos que podría tener una fórmula como la de DwORKIN sería acaso que el primer valor de lo político no sería un valor vacío, sino dotado de cierto contenido sustantivo; y éste sería un atractivo que quizá podríamos extender también al más genérico uso del término «igualdad» para designar a la justicia, en la medida en que sugiera esa igualdad fáctica entre los seres humanos a la que DwORKIN se refiere. Más de una vez se ha insistido en que la justicia es un valor vacío o puramente formal y puede resultar paradójico, si no desorientado, proponer la renuncia a un valor pretendidamente sustantivo como el de la igualdad en el nombre de un valor que no lo es, como el de la justicia.

Un par de observaciones pueden ayudar a disolver esta supuesta paradoja. La primera es que la justicia, definida en los términos aristotélicos, es ciertamente un valor formal, en el sentido de que sólo determina una forma o estructura de acuerdo con la cual comportarnos o articular normas; es decir, la justicia así definida no contiene un criterio para determinar quiénes son iguales y quiénes no lo son, ni tampoco un criterio para determinar el trato sustantivo concreto que unos y otros merecen. La idea de justicia presupone o requiere esos criterios, pero no los suministra. Por eso llevan razón quienes sostienen que la sola idea de la justicia es insuficiente para decidir controversias morales o jurídicas.

La segunda observación es que la idea de igualdad es formal exactamente en el mismo sentido en el que lo es la idea de justicia. Así, por ejemplo, Westen ha demostrado que las decisiones del Tribunal Supremo norteamericano basadas sobre el papel en la decimocuarta enmienda de la Constitución de ese país («ningún estado denegará a persona alguna bajo su jurisdicción la igual protección de las leyes») siempre se apoyan, en realidad, en otros derechos constitucionales sustantivos y nunca en dicha cláusula como tal, porque resulta ser una cláusula vacía, en tanto que constituye una instancia del principio general de igualdad ${ }^{19}$. Por eso, propone que se renuncie al lenguaje de la igualdad y se opte por el lenguaje de los derechos sustantivos ${ }^{20}$.

16 SEN, 2004: 15, 26 y 137.

17 RAWLS, 1973:3.

18 RAZ, 1986: 228.

19 WESTEN, 1982: 559-577.

${ }^{20}$ En lo que toca al control de constitucionalidad, puede encontrarse una proposición curiosamente opuesta a la de WESTEN en CALABRESI, 1991: 91-103. 
Aquí puede discutirse, como ha hecho Ruiz Miguel, cuál es el sentido de la formalidad de la igualdad, si realmente conlleva vacuidad o si, por el contrario, es posible derivar de ella algún contenido. $\mathrm{O}$, lo que es lo mismo, cuáles son los términos de la relación entre el concepto y las concepciones de la igualdad ${ }^{21}$. La cuestión no es nueva y remite a los intentos de derivar contenidos a partir de formas. En el ámbito del pensamiento jurídico evoca la noción de la moral interna del derecho de FULLER y su defensa de la conexión entre la forma jurídica y la justicia material, una defensa ya anticipada por HAYEK y a la que se han unido muchos otros a la hora de buscar y encontrar un fundamento moral para el rule of law, el imperio de la ley o la seguridad jurídica, llegando a conclusiones diversas aunque próximas ${ }^{22}$. A mi juicio, esta conexión es de muy problemático establecimiento si se lleva más allá de los moderados términos propuestos por RUIZ Miguel para el concepto de igualdad, a saber, que el concepto de igualdad, aunque formal, no está vacío del todo porque determina dos limites a sus posibles concepciones. Un primer límite, conceptual, constituido por la interdicción de la arbitrariedad o por la exigencia de imparcialidad, y un segundo límite, contextual o pragmático, constituido por la implausibilidad de ciertos criterios de valoración o de relevancia, que, en un contexto histórico y cultural determinado, no serían admisibles de ningún modo.

En todo caso, no hace falta entrar a fondo en este asunto de la conexión entre concepto y concepciones, o entre forma y contenido, porque cualquier conclusión a la que lleguemos con respecto a la igualdad vale también para la justicia, dado que el problema planteado es el mismo y los argumentos que se manejan son los mismos. En particular, ese contenido mínimo que RuIz MiguEL atribuye al concepto de igualdad se lo podría atribuir sin duda al concepto de justicia. Como consecuencia, la opción por la igualdad frente a la justicia no supone la opción por un valor que sea en ningún sentido de más densa sustancia, a salvo, como decía, de la afirmación taxativa de la igualdad fáctica de todos los seres humanos que está incluida en el derecho a igual consideración y respeto de DwORKIN, y que parece ser uno de esos límites contextuales que ninguna concepción de la igualdad puede franquear, pero que también podría incluirse, por qué no, en un concepto de justicia contextual o pragmáticamente orientado. Sin embargo, sigo pensando que RAz lleva razón en cuál es el precio que hay que pagar a cambio de ese posible atractivo.

\subsection{Igualdad fáctica}

La tercera premisa afirma la igualdad básica o radical de todos los humanos. Aquí la igualdad aparece como juicio de hecho sin significado axiológico intrínseco. Lo que se afirma es que, de hecho, todos los seres humanos (es decir, todos los miembros de cierta clase) son iguales desde cierto punto de vista, dado que todos ellos comparten la posesión de cierta cualidad. Cuál sea esa cualidad es irrelevante al efecto de determinar que lo que se afirma es un hecho, el hecho de que la cualidad pertenece a todos los miembros del género humano.

21 Ruiz Miguel, 2002: 693 y ss.

22 HAYeK, 1995: 114 y ss.; Fuller, 1969: 153 y 162; FinNIS, 1980: 271-272; SuMMERS, 1993: 139-140; WeINRIB, 1995; Allan, 2001: 60-61; GARZÓN VALDÉS, 1993: 312-313; EsCUdERO, 2000; ARCOS, 2001: LAPORTA, 2002: 127-128. Un análisis crítico, en GARCía MANRIQUE, 2003. 
Ahora bien, en el caso de una teoría de los derechos, la cualidad que se destaca como común a todos los humanos resulta ser una cualidad considerada valiosa, la cualidad que consiste en la capacidad para llevar una vida libre. Es la posesión de esta cualidad la que nos hace merecedores de la atribución de ciertos derechos, y es la posesión de esta cualidad la que permite calificarnos como dignos, como titulares de la «dignidad humana». Esta dignidad, dicho sea de paso, no es «un» valor, sino un término que expresa «el» valor que poseen los seres humanos en tanto capaces de ser libres; expresa la especial calidad valiosa de los mismos. Por eso, es un error pensar en la dignidad como un valor más junto con la libertad, la justicia o cualesquiera otros. Decir «los seres humanos son dignos» (porque son capaces de ser libres) es algo así como decir «los jarrones chinos son valiosos» (porque son bellos). Por eso, el concepto de dignidad humana se vuelve inútil cuando detrás de él no hay una explicación de por qué los seres humanos son valiosos. En cambio, cuando la hay, el concepto es útil porque es informativo y porque permite extraer consecuencias normativas. Tienen razón, pues, R. MACKLIN cuando critica el concepto «dignidad» por su inutilidad, o S. PINKER cuando lo considera «estúpido», pero sólo la tienen en los casos (eso sí, muy frecuentes) en que la dignidad se afirma como dogma no justificado ${ }^{23}$.

Los derechos que se nos atribuyen según una teoría de los derechos fundamentales son aquellas facultades (derechos en sentido estricto, o libertades, o inmunidades, o potestades) que favorecerán nuestra capacidad para llevar una vida libre. Así hay que interpretar, me parece, la proclamación con la que se inicia la Declaración de los derechos del hombre y del ciudadano aprobada por la Asamblea Nacional francesa en 1789: «Los hombres nacen y permanecen libres e iguales en derechos». Dejando de lado el tono iusnaturalista que a algunos puede no gustar, lo que se dice aquí es que todos los seres humanos nacen con la capacidad de ser libres y que, para poder disfrutar o potenciar esa capacidad, han de disfrutar de ciertos derechos. Éste es el contenido esencial de toda teoría de los derechos.

Una teoría de los derechos no tiene por qué restringir la igualdad humana sólo a la capacidad para llevar una vida libre. De hecho, estará interesada en conocer en qué otras cosas son iguales los humanos, cuáles son sus características, para poder determinar qué derechos les son necesarios para poder desarrollar dicha capacidad. Seguramente toda teoría de los derechos aceptará esa más amplia igualdad de las facultades del cuerpo y de la mente a la que se refiere HOBBES y que constituye uno de los pilares (fácticos) de su teoría política ${ }^{24}$. Sin embargo, esta amplia igualdad, de por sí, no podría justificar derechos, como no los justificaría si la predicásemos de otros seres distintos de los humanos. También, digamos, las hormigas son iguales en las facultades del cuerpo y de la mente (si es que tienen mente), pero no por ello les atribuimos derechos. Lo relevante es, repito, la capacidad para llevar una vida libre, que parece ser que las hormigas no poseen y los humanos sí; pero, de por sí, ninguna igualdad meramente fáctica, por extensa o profunda que sea, puede justificar la atribución de derechos.

23 MACKLIN, 2003; PINKER, 2008.

${ }^{24}$ Hobbes, 1980: I, 13. «La Naturaleza ha hecho a los hombres tan iguales en las facultades del cuerpo y del espíritu que, si bien un hombre es, a veces, evidentemente, más fuerte de cuerpo o más sagaz de entendimiento que otro, cuando se considera en conjunto, la diferencia entre hombre y hombre no es tan importante que uno pueda reclamar, a base de ella, para sí mismo un beneficio cualquiera al que otro no pueda aspirar como él». 
Sin embargo, de una igualdad meramente fáctica es de la que ahora estamos hablando («los seres humanos son básicamente iguales en ciertos aspectos»), y no de un supuesto valor de la igualdad. Que la cualidad o cualidades en cuestión (esos «aspectos») hagan valiosos a sus poseedores (los hagan «dignos») no implica que haya nada valioso en esa igualdad, ni que esta tercera premisa que estamos analizando constituya un juicio de valor, porque sólo afirma que los seres humanos «son así y así». Del mismo modo, no es un juicio de valor el que afirma que «el ser humano y la hormiga son diferentes en esto y en esto», que es fáctico, como lo es el que afirma «el ser humano y la hormiga son iguales en esto y en esto» o «los seres humanos son iguales, entre sí, en esto y en esto». Sí es un juicio de valor el que afirma «el vino contenido en esta botella es bueno», pero no el que afirma que «el vino contenido en esta segunda botella es igual de bueno que el contenido en la primera», aunque, de ambos, podemos deducir, claro está, otro juicio de valor: «el vino contenido en esta segunda botella es bueno»; o «todas las botellas que contengan este mismo vino son botellas de vino bueno». También en este caso lo que hacemos es juzgar la pertenencia de ciertas propiedades fácticas a dos o más objetos (aquellas propiedades que permiten afirmar que nos hallamos ante «el mismo» vino); otra cosa distinta es juzgar que tales propiedades son generadoras de valor.

No obstante, uno podría sostener que no hay enunciados de igualdad puramente fácticos o descriptivos, porque todo enunciado de igualdad que atañe a personas, cosas o acciones presupone un criterio de relevancia, es decir, la selección previa de una propiedad que servirá de base a la comparación, base a su vez del enunciado de igualdad. Pero esta selección de la propiedad relevante es siempre el fruto de una evaluación (sea moral, estética o de otro tipo) ${ }^{25}$. En efecto, si los enunciados comparativos (y los de igualdad lo son) tienen algún interés práctico es el de orientar nuestras elecciones o definir nuestras preferencias, de manera que solemos formularlos de acuerdo con aquella propiedad que, de cara a nuestro acto de elegir o de preferir, consideramos relevante. Por seguir con el ejemplo del vino, es evidente que no es posible formular enunciado comparativo alguno acerca de qué vino es mejor si antes no he determinado qué significa que un vino es bueno, es decir, si no he determinado la propiedad relevante, y esto tiene sentido si la calidad del vino orienta mi elección o mi preferencia. Por tanto, en la medida en que un enunciado de igualdad es un enunciado comparativo que orienta una elección o una preferencia, podríamos decir que es un enunciado prescriptivo. Según esto, un enunciado de igualdad sólo sería descriptivo si se formulase de acuerdo con una propiedad de cuya relevancia no sabemos nada, o con una propiedad de la que sabemos precisamente que no es relevante (para elegir o preferir).

Sin embargo, me parece que éste es un sentido muy amplio de «enunciado prescriptivo», porque sigue siendo cierto que lo que se hace en estos casos es describir un estado de cosas, la pertenencia a dos personas, cosas o acciones de una misma propiedad, aunque esa descripción tenga, en última instancia, un fin prescriptivo. Quizá se ve mejor cuando la propiedad relevante es puramente fáctica, por ejemplo, a la hora de comprar un coche, su número de plazas. Ha de resultar evidente que los enunciados «este coche tiene las mismas plazas que este otro» o «este coche tiene más plazas que este otro» son enunciados descriptivos puros. Puede que, para mí, el número de plazas

25 Ruiz Miguel, 2002: 687. 
sea una propiedad relevante, incluso la más relevante, y que determine mi compra, pero no por ello deja de ser descriptivo el enunciado; el enunciado sigue siendo el mismo para quien no tiene ningún interés en el número de plazas del vehículo que pretende adquirir, es decir, el enunciado, de por sí, no es una razón para la acción, no prescribe nada. Por supuesto, la relevancia que yo atribuyo a un dato fáctico como el número de plazas viene determinada por algún tipo de juicio prescriptivo, del tipo «yo deseo llevar en el coche a un cierto número de personas» o «es bueno que yo lleve en el coche a un cierto número de personas», pero esto tampoco altera el carácter descriptivo del enunciado acerca del número de plazas del coche.

Esto vale también para los enunciados de igualdad en los que se omite la referencia a al criterio de comparación, cuando se dice, por ejemplo, «estos dos coches son iguales» (porque tienen el mismo número de plazas), o para los enunciados de igualdad en los que se conecta la igualdad el criterio de comparación, diciendo «estos dos coches son iguales porque tienen el mismo número de plazas». Su fuerza prescriptiva depende de la relevancia que atribuyamos al criterio de comparación, de manera que sigue siendo cierto que para quien no otorga relevancia alguna al número de plazas el enunciado sigue siendo puramente descriptivo. Por tanto, yo diría que hay enunciados descriptivos que pueden tener fuerza prescriptiva, pero no por sí mismos, sino en conexión con un enunciado prescriptivo. Por eso, es cierto que un enunciado de igualdad formulado de acuerdo con un criterio de relevancia descriptivo no puede ser un enunciado prescriptivo de igualdad ${ }^{26}$. Pero esto es lo que sucede con el enunciado «los seres humanos son iguales porque son capaces para la libertad», que, de por sí, no puede ser prescriptivo porque está formulado de acuerdo con un criterio de relevancia descriptivo. Es sólo porque conectamos este enunciado con algún otro de carácter prescriptivo (del tipo «se debe promover la capacidad para la libertad» $\mathrm{o}$ «la capacidad para la libertad es valiosa»), por lo que el enunciado descriptivo de igualdad de los seres humanos adquiere, por así decir, fuerza prescriptiva.

Por tanto, el hecho de que los seres humanos sean iguales entre sí en ciertas propiedades no es, pues, como tal, ni bueno ni malo. De todos los seres humanos puede afirmarse que son bípedos implumes, y esto, bueno no parece que sea, ni malo tampoco. Tampoco es bueno que todos los seres humanos sean iguales en su capacidad para la libertad, o en cualquier otra cosa. Simplemente, parece que es así. ¿Sería bueno, o malo, detectar que existen otros seres racionales además de los seres humanos? Las preguntas acerca de si existen seres racionales en otros planetas, o si seremos capaces de crear robots racionales, ¿'son preguntas morales en sí? No; son preguntas acerca de cómo es la realidad, aunque de su respuesta puede depender la toma de decisiones que sí son moralmente relevantes, como la de extender a un marciano o a un robot el estatuto que atribuimos a los seres humanos.

Si esto es así, y como resultado de la asunción de la tercera premisa, toda teoría de los derechos es una teoría igualitaria, ahora porque se basa en cierta igualdad de todos los humanos. Lo cual no supone considerar a la igualdad como un valor, sino aceptar una constatación fáctica, sobre la que (junto con otras bases) se construirá la atribución de derechos a todos los miembros de la especie humana.

26 Ruiz Miguel, 2002: 687. 
Un juicio fáctico de igualdad de este tipo es el que formula RAWLS para justificar por qué los derechos básicos deben ser atribuidos a todos los seres humanos y no sólo a algunos de ellos. La razón es que todos ellos, salvo excepciones, son agentes morales, puesto que poseen capacidad para elegir una concepción de lo bueno y para actuar de acuerdo con el sentido de la justicia ${ }^{27}$. Uno puede, como SINGER, discrepar de esto, y sostener que:

«La posesión de una personalidad moral no constituye una base satisfactoria para el principio de que todos los seres humanos son iguales» ${ }^{28}$.

Quizá SINGER esté pensando en que existen miembros de la especie humana que carecen de personalidad moral (sin duda así es) o en que existen miembros de otras especies que la poseen en alguna medida (probablemente así sea); o quizá piense que la personalidad moral no es la propiedad más relevante que tenemos en común los humanos. El caso es que, a cambio, SINGER propone que la «base de la igualdad humana» radique en la igual consideración de todos los intereses, tanto si son humanos como si no. Sin embargo, esta diferente fundamentación de la base de la igualdad humana sigue radicando en la idea de la justicia: tratar o considerar igual los intereses que son iguales; y sigue requiriendo un juicio fáctico consistente en determinar cuáles intereses son iguales y cuáles son diferentes. Probablemente los intereses humanos sean, en buena parte, muy diferentes de los de otros animales, e iguales entre sí.

Quiero detenerme un poco más en este punto, porque no parece que todos acepten que una teoría de los derechos descanse necesariamente sobre una premisa igualitaria fáctica y sí, en cambio, en un supuesto valor de la igualdad. A mi juicio, si los humanos no fuesen fácticamente iguales en el aspecto señalado (capacidad para llevar una vida libre o, con RAWLS, capacidad para la agencia moral, dos capacidades que vienen a ser la misma, como ya lo dejó escrito KANT) ${ }^{29}$, una teoría de los derechos no tendría sentido (o no sería una teoría de la justicia) porque no tendría sentido (o no sería justo) adscribir iguales derechos, concebidos como instrumentos de la libertad (tal como lo son), a seres que no son igualmente capaces para la libertad. Por el contrario, GONZÁLEZ AMUCHASTEGUI, autor de una muy completa y atractiva teoría de los derechos humanos, escribe:

«Los defensores de la igualdad —entre otros, los defensores de los derechos humanos- no están tan preocupados por demostrar que los seres humanos seamos iguales, como por luchar para que, seamos iguales o no, seamos tratados como iguales. Dicho con otras palabras, el defensor de la igualdad no está preocupado por saber si el cociente intelectual de los varones esquimales es igual al de las mujeres nativas de Papúa-Nueva Guinea $[\ldots$.$] y, por ello, unas eventuales conclusiones desigualitarias en estas investigaciones [...] no$ le harían abandonar sus convicciones igualitarias ni adscribir los derechos y obligaciones de manera diferente».

AMUCHASTEGUI continúa explicando que la afirmación de que las personas son iguales por naturaleza puede inducir a error, «pues presenta como natural, es decir, como un elemento característico del mundo del ser -y, por tanto, verificable empíricamente- lo que realmente es una propuesta normativa»; y un poco más adelante se

\footnotetext{
27 RaWLS, 1973: 505. También HIERRO, 2000: 359-360; o De LORA, 2006: 145 y 191; entre otros muchos.

28 SINGER, 1991, 30.

29 KANT, 1996: 223-225.
} 
refiere a las necesidades humanas básicas, que considera iguales para todos, pero que no se determinan a partir de ninguna constatación fáctica, sino a partir de los «fines básicos del ser humano», que son, a su vez, determinados por la moral. En el caso de su propuesta, ese fin básico de todos los seres humanos es su «pleno desarrollo como agentes morales racionales» ${ }^{30}$. Esta forma de concebir la igualdad humana, como propuesta normativa en vez de como hecho, no es excepcional sino que está bastante extendida, como acreditan las notas que acompañan el texto citado.

Pues bien: lo que acaso es una propuesta normativa no puede ser el hecho de la igualdad o diversidad de los seres humanos, sino la consideración como irrelevantes de las evidentes diferencias que pueden, de hecho, percibirse entre ellos. Esta consideración puede entenderse como normativa porque está en la base de la construcción de normas. Una norma, digamos, atribuye una consecuencia a un grupo de casos y, para ello, debe seleccionar el elemento relevante a partir del cual se identifica ese grupo de casos. Pero tal consideración normativa tiene que asentarse en una previa consideración fáctica acerca de cómo son unos y otros casos, en qué se parecen y en qué se diferencian. Si, de cara a la formulación de normas que atribuyen derechos, uno selecciona la clase de los humanos y no otra clase cualquiera, ha de ser porque los miembros de la clase de los humanos poseen en común la cualidad relevante al efecto de atribuir derechos. ¿Qué ventaja moral podría haber en tratar como iguales a quienes, de hecho, son diferentes?

Los vicios normativos de la sobreinclusión y la infrainclusión se ponen de manifiesto precisamente cuando se comprueba que el juicio fáctico que sirvió para la definición de la clase a la que se aplicará la norma era un juicio imperfecto. En el caso que nos ocupa, si la propiedad relevante es la capacidad para ser libre, o la agencia moral, una instancia de sobreinclusión es la de los humanos en estado de muerte cerebral, o en ciertos estados vegetativos, porque, siendo humanos, no presentan la propiedad relevante; y una instancia de infrainclusión es la de los replicantes de Blade Runner, la película de Ridley Scott, quienes, no siendo humanos, sí presentan la propiedad relevante. Pero parece claro que es un juicio de hecho el que nos lleva a observar que la muerte cerebral es incompatible con la agencia moral o que los replicantes son capaces de agencia moral tanto o más que los seres humanos. Tan juicio de hecho como el que previamente nos ha llevado a adscribir los derechos a la clase de los humanos y no a otra clase distinta. Por eso KANT, cuando construye los fundamentos de su filosofía moral, se refiere con insistencia a «todos los seres racionales» y no sólo a los seres humanos; porque lo relevante no es el hecho biológico de pertenecer a la especie humana, sino el hecho de poseer una naturaleza racional ${ }^{31}$. En definitiva, hay un hecho habilitante de toda teoría de los derechos, y es el de que los seres humanos son básicamente iguales en aquello que, además, los hace valiosos: su capacidad para la libertad o para la moralidad.

Cuando decimos «básicamente» iguales estamos diciendo dos cosas: una, que las diferencias en la capacidad para la libertad o para la moralidad de los seres humanos son muy pequeñas si las comparamos con las diferencias en esas mismas capacidades

30 GonZÁlez Amuchastegui, 2004: 228-229.

31 KANT, 1996: 108, 181, 187 o 235. 
entre los seres humanos y los no humanos (ahora dejando aparte a los replicantes y otros seres por el estilo, que, si apareciesen, serían sin duda merecedores de los mismos derechos humanos); y otra, que los seres humanos carecen de esa capacidad sólo excepcionalmente, en casos patológicos, o bien cuando están en trance de adquirirla (en la infancia). Si, de otra manera, los varones esquimales y las mujeres de PapúaNueva Guinea fueran muy diferentes en este aspecto, que no lo son, una teoría de los derechos se enfrentaría a un problema muy grave, tanto que debería conducir a la desaparición de la propia categoría de los derechos «humanos» tal y como la conocemos. Más precisamente: si las diferencias de cociente intelectual entre unos y otras llegasen más allá de cierto límite, no tendría sentido atribuirles a unos y otras los mismos derechos.

Tampoco importa mucho que las necesidades humanas básicas se determinen a partir de fines que son, a su vez, determinados normativamente. Esto tiene más bien que ver con la definición de cuáles han de ser los derechos atribuidos, y no tanto con a quién se atribuyen, si presuponemos que esos fines son específicamente «humanos». $\mathrm{Si}$, por ejemplo, el fin último de lo humano fuese la jardinería, quizá tendríamos que redefinir nuestras necesidades básicas, y así los derechos; pero seguiría siendo necesario formular un juicio fáctico de igualdad acerca de quién sería titular de tales derechos: quizá todo aquel que se muestre capaz de ser un buen jardinero (todos los seres humanos si de veras poseemos esa capacidad, pero también algunos robots de Isaac Asimov). De manera que la determinación de las necesidades humanas básicas a partir de fines normativamente determinados no altera el hecho de que el juicio acerca de la igualdad entre los seres humanos sea un juicio fáctico. Como dije antes, este juicio fáctico, de por sí, no habilita la concesión de derechos, pero la premisa normativa que es necesaria para tal habilitación no tiene nada que ver con la igualdad, sino con el valor que atribuimos a la libertad y, por tanto, a los seres capaces de ser libres, sean éstos los que sean.

Algo que puede recordar a la comparación entre varones esquimales y mujeres de Papúa-Nueva Guinea lo encontramos en el arranque de uno de los libros de A. SEN sobre la igualdad, que comienza haciendo notar la «básica heterogeneidad de los humanos», que son «profundamente diversos» ${ }^{32}$. Hay que suponer que SEN, como AmUCHASTEGUI, y aunque no lo diga, da por supuesta la básica homogeneidad y la escasa diversidad de los humanos, si los comparamos con otros seres, y que tiene interés en destacar que, a pesar de ello, los humanos muestran, entre sí, diferencias relevantes para la justicia. De hecho, el valor de la justicia presupone la capacidad para discernir lo relevantemente desigual, e incluso las teorías de los derechos, que se centran en lo relevantemente igual, suelen habilitar un espacio para la consideración de la desigualdad relevante, y de ahí la categoría, quizá contradictoria en su denominación pero muy sensata, de los derechos humanos específicos (por ejemplo, los derechos de las mujeres ${ }^{33}$. En todo caso, uno y otro juicio, el de la homogeneidad y el de la heterogeneidad, son juicios fácticos por mucho que sean formulados a la luz de propiedades cuya relevancia es determinada normativamente. En definitiva, si lo que se quiere decir es que, para tratar justamente a las personas, hay que ser cons-

32 SEN, 2004: 13.

33 García Manrique, 2004. 
cientes de sus diferencias, o incluso que una teoría de los derechos debe dar cabida a ciertas diferencias entre las personas, dígase eso. No se diga, en cambio, que la (aproximadamente) igual capacidad para la libertad que muestran los seres humanos no es un hecho. Lo es, y de la máxima importancia. Lo que no es un hecho es que otorguemos relevancia moral a esa capacidad y a las diferencias vinculadas con ella y no se la otorguemos a otras diferencias observables con la misma o mayor facilidad (la raza, la orientación sexual, el color del pelo). Este otorgar o no relevancia a unas $\mathrm{u}$ otras circunstancias de lo humano es una exigencia de la justicia y no del supuesto valor de la igualdad.

\section{LA IGUALDAD ANTE LA LEY}

Hasta aquí hemos podido comprobar que las teorías de los derechos, que son teorías típicamente igualitarias, lo son hasta en tres sentidos al menos, pero ninguno de ellos requiere el concurso del valor de la igualdad. Hemos podido advertir que lo normativo es igualitario, que la justicia es igualitaria, y que los seres humanos son iguales en ciertos aspectos, pero nada de eso requiere convertir a la igualdad en un valor, ni presuponer que lo sea. Nos hemos detenido en recalcar el carácter fáctico del juicio de igualdad acerca de la forma de ser de los humanos y en observar que el término «igualdad», cuando cobija un genuino valor, es el de la justicia. Ahora daremos un paso más y examinaremos las dos variantes principales de la igualdad considerada como valor, a saber, la igualdad formal y la igualdad material o, mejor, la igualdad ante la ley y la igualdad de bienestar, recursos u oportunidades. En una teoría de los derechos, ambas igualdades aparecen de alguna manera, bien sea como valores, como principios o como derechos (esto ahora no importa mucho, siempre que se tenga en cuenta que andamos en busca de cuál puede ser su valor intrínseco); más allá de este tipo de teorías, no cabe duda de que la igualdad formal y la igualdad material son moneda corriente en el discurso político. Veamos qué significa cada una de ellas y, a partir de ahí, tratemos de determinar qué posible valor moral hemos de atribuirles, siempre con el objetivo de poder responder a la pregunta sobre el estatuto axiológico de la igualdad.

La igualdad ante la ley es tan clásica como la Declaración de los derechos del hombre $y$ del ciudadano, cuyo art. $6 .^{\circ}$ establece:

«La ley es la expresión de la voluntad general. Todos los ciudadanos tienen el derecho de participar directamente o por medio de sus representantes en su formación. Debe ser la misma para todos, tanto si protege como si castiga. Todos los ciudadanos, al ser iguales ante ella, son igualmente admisibles a todas las dignidades, puestos y empleos públicos, según su capacidad y sin otra distinción que la de sus virtudes y la de sus talentos».

Y la Constitución española, en su art. 14, dice:

«Los españoles son iguales ante la ley, sin que pueda prevalecer discriminación alguna por razón de nacimiento, raza, sexo, religión, opinión o cualquier otra condición o circunstancia personal o social».

Dejando de lado otros contenidos del art. . $^{\circ}$ de la Declaración francesa, fijémonos en que puede significar «igualdad ante la ley» en cualquiera de los dos textos citados. 


\subsection{Igualdad lógica (o justicia formal)}

En un primer sentido, la igualdad ante la ley consiste en que las normas sean aplicadas igualmente a todos, sin tener en cuenta otras circunstancias que las establecidas en la propia norma. Esto es, que si la norma establece que «aprobarán todos los alumnos que saquen al menos un cinco», atenta contra la igualdad ante la ley aprobar a un alumno que ha sacado un cuatro pero que nos ha regalado un jamón o suspender a otro que ha sacado un seis pero al que tenemos ojeriza. Y si la norma establece que «todos los extranjeros en situación irregular serán confinados en centros de internamiento», también atenta contra la igualdad ante la ley quien, estando encargado de aplicarla, evita hacerlo con cierto extranjero en situación irregular por razón de la compasión, la solidaridad o la justicia. Este tipo de igualdad parece que no es sino la igualdad lógica contenida en la misma idea de norma o, mejor en este caso, en la misma idea de «aplicación de una norma», puesto que aparece en el momento de la aplicación de las normas, y no en el de su formulación. En efecto, y como escribe ALEXY, el mandato de igualdad en la aplicación del Derecho

«exige que toda norma jurídica sea aplicada a todo caso que cae bajo su supuesto de hecho y a ningún caso que no caiga bajo él, es decir, que las normas jurídicas tienen que ser obedecidas. Pero que las normas jurídicas tienen que ser obedecidas ya lo dicen ellas al expresar un deber ser» ${ }^{34}$.

KELSEN advirtió en su día de que este principio de igualdad ante la ley, o principio de legalidad, «nada tiene que ver con la justicia» ${ }^{35}$, aunque ya hemos visto, en la sección precedente, que no todos comulgan con esta opinión. No lo hacen los partidarios del valor moral de la justicia formal, que, recuérdese, consiste en el trato igual de los casos considerados iguales por la norma y en el trato desigual de los casos considerados desiguales por la norma, y esto con independencia de que los casos considerados iguales o desiguales por la norma merezcan efectivamente tal consideración (esto es, con independencia de que la norma sea sustancialmente injusta) ${ }^{36}$. Creo que hay buenas razones para descartar el valor moral de la justicia formal ${ }^{37}$; también las hay para darse cuenta de que el valor que encontramos a menudo en el respeto a normas que son materialmente injustas es precisamente el valor de la justicia material, realizado en el respeto a la expectativa generada por la norma ${ }^{38}$. Sin embargo, no es necesario examinar este asunto aquí, porque el valor que está en juego es, en todo caso, el de la justicia y no el de la igualdad, es decir, incluso si concluyésemos que la igualdad ante la ley, en este sentido, es moralmente valiosa, lo haríamos porque participa del valor de la justicia, con lo que la apreciación de su moralidad no requeriría la afirmación del valor de la igualdad.

Obvia como pueda parecer, esta exigencia de la igual aplicación de la ley está lejos de resultar satisfecha en la práctica jurídica, porque, como también apunta ALEXY,

34 AleXy, 1993: 382.

35 KELSEN, 1991: 51.

36 Quien esté interesado en cómo se argumenta el valor de la justicia formal puede consultar RADBRUCH, 1974: 44; Fuller, 1969: 155; HaRT, 1980: 255; CAMPBEll, 2002, cap. 2, o Ruiz Miguel, 1997.

37 LYONS, 1993; SCHAUER, 1991: 137.

38 García Manrique, 2003: 507. 
aunque su núcleo es simple, «el mandato de igualdad en la aplicación del derecho presenta una estructura complicada» ${ }^{39}$. Esto se debe a que las mismas normas son aplicadas por órganos judiciales distintos y a que, muy a menudo, el significado de las normas no es unívoco (sobre todo cuando contienen conceptos imprecisos, cosa que es frecuente e incluso deseable), de manera que casos iguales son juzgados de manera diferente, porque distintos jueces o tribunales han interpretado la norma aplicable de manera distinta. El remedio de esta diversidad no es sencillo, porque anda de por medio el principio de la independencia judicial, uno de los considerados básicos en la estructura del Estado de Derecho, que parece autorizar a los jueces para interpretar las normas según su propio criterio (cosa, por cierto muy discutible) ${ }^{40}$. La disposición jerárquica del poder judicial y el sistema de recursos permite que, en ocasiones, la jurisprudencia de los tribunales superiores unifique la interpretación de las normas, pero eso no siempre llega a suceder, por diversas razones: no todos los asuntos pueden ser recurridos ante el Tribunal Supremo, o quizá éste no lleva a cabo su labor de unificación de la interpretación normativa, o quizá todavía no ha habido ocasión para ello...

El Tribunal Constitucional español, siendo consciente seguramente del largo alcance que podría llegar a tener la aplicación del principio de igualdad en la aplicación ante la ley, ha restringido, y mucho, este principio, distinguiéndolo de la univocidad interpretativa. Su jurisprudencia al respecto es muy abundante, pero podemos guiarnos por su Sentencia 144/1988, de 12 de julio, que es particularmente clara, concisa y significativa. En ella se establece que:

«La igualdad ante la ley que consagra el art. 14 de nuestra Constitución exige [...] que ésta sea aplicada por igual a todos, sin que en ningún caso puedan ser unos dispensados de su cumplimiento en atención a sus condiciones personales o tratados otros con mayor rigor también en consideración de sus personas [...] Cosa bien distinta es, sin embargo, que del principio de igualdad se derive la exigencia absoluta de que todos los órganos judiciales interpreten siempre del mismo modo la ley [...] Esta exigencia [...] no tiene como objetivo la igualdad ante la ley, sino la univocidad de los preceptos legales».

Esta exigencia, continúa argumentando el Tribunal, es requerida por el principio de seguridad jurídica establecido por el art. 9.3 de la Constitución, y no por el principio de igualdad ante la ley, y además ha de alcanzarse sin menoscabo de la independencia judicial, el principio que supuestamente autoriza la autonomía del juez a la hora de interpretar las normas. Por eso, resulta que, según la misma sentencia:

«Cuando a pesar de las instituciones procesales destinadas a evitarlas o corregirlas se producen divergencias interpretativas, éstas no entrañan, sin embargo, en sí mismas, una quiebra del principio de igualdad ante la ley, pues la ley diversamente interpretada por los distintos jueces o incluso por un mismo juez, en diversos momentos, es aplicada, sin embargo, por igual siempre que en tal aplicación no se tomen en consideración [...] diferencias personales a las que la ley misma no conceda relevancia».

En la práctica, esto viene a significar que la igualdad ante la ley sólo se vulnera cuando un mismo órgano judicial cambia de criterio sin aparente justificación. Si, en cambio, casos iguales son juzgados de manera distinta por distintos órganos judiciales, o incluso por un mismo órgano pero mediando una justificación para el cambio de

39 Alexy, 1993: 382.

40 FERRERES, 2009: 60-66. 
criterio, no existe tal vulneración. Es más, tal justificación, según el Tribunal Constitucional, puede tener cualquier contenido, e incluso ser meramente implícita, de manera que, en realidad, basta con que el cambio de criterio no sea expresamente arbitrario. Lo cual supone que la igualdad ante la ley deja de significar, como parecía evidente, que la misma ley se aplique igual a todos, y pasa a significar que la misma ley se aplique igual a todos: 1) por parte de un mismo órgano judicial, y 2) siempre que éste no justifique lo contrario de alguna manera. El resultado de esta doctrina es que casos exactamente iguales, a los que se aplica la misma norma, y que son resueltos de manera distinta, incluso por parte de un mismo órgano judicial, no suponen la violación de la igualdad ante la ley. Se trata de un resultado sorprendente y decepcionante, y podemos estar de acuerdo en que:

«La consideración del Poder Judicial que se desprende de las condiciones exigidas para aplicar aquel criterio (el del TC), como un conjunto de unidades discretas y no como un todo unitario, constituye, a mi modo de ver, una solución insatisfactoria desde el punto de vista de la igualdad de los ciudadanos ante la ley» ${ }^{41}$.

Cabe añadir que la mejor forma de explicar el sentido de esa insatisfacción es hacer ver que el criterio del Tribunal Constitucional da lugar a resultados injustos. Lo que irrita a los ciudadanos es que los jueces les traten según un tipo de desigualdad que puede calificarse como injusta; es en esta injusticia, y no en la desigualdad como tal, en la que radica la insatisfacción moral.

\subsection{Igualdad sustantiva (o justicia material)}

En un segundo sentido, la igualdad ante la ley es una exigencia dirigida al legislador y no al juez, dirigida a la ley y no a su aplicación. No se trata, ahora, de una igualdad formal o lógica, sino una igualdad sustantiva determinada que aparece en un momento histórico igualmente determinado, el del declive de la sociedad estamental hacia finales del siglo XVIII. Su significado era la prohibición de discriminación jurídica por razón de la pertenencia a uno u otro estamento ${ }^{42}$. Esto es lo que quería erradicar ese art. 6. ${ }^{\circ}$ de la Declaración francesa de derechos que he transcrito antes, por mucho que su enunciado fuese mucho más genérico y, por tanto, permitiese una interpretación mucho más extensa (por ejemplo, con la intención de erradicar la discriminación racial o sexual), aunque, seguramente, no fue prevista de antemano. La misma idea la expresó KANT pocos años después, en 1793, al definir la «igualdad según el derecho» como que:

«A cada miembro de la comunidad le ha de ser lícito alcanzar dentro de ella una posición de cualquier nivel (de cualquier nivel que corresponda a un súbdito) hasta el que puedan llevarle su talento, su aplicación y su suerte».

No debe asustar la alusión a la condición de súbdito, que aquí simplemente se contrapone a la de soberano. La igualdad la refiere KANT al súbdito, pero cada miembro

41 Ruiz Miguel, 1996: 75. Las pp. 69-75 de este trabajo contienen un resumen bueno y crítico de esta doctrina. Otro resumen bueno, aunque no tan crítico, pero más reciente, se encuentra en GIMÉNEZ GLÜCK, 2004: 44-52.

42 BobBIo, 1993: 72; De LuCAS, 1996: 496. 
de la comunidad es al mismo tiempo ciudadano en tanto que colegislador. KANT aclara a continuación que la igualdad según el derecho se basa en que:

«Como el nacimiento no es una acción por parte del que nace, y consiguientemente no puede acarrear a éste ninguna desigualdad de estado jurídico [...] resulta que no puede haber ningún privilegio innato de un miembro de la comunidad [...] sobre otro» ${ }^{43}$.

Esto es la igualdad ante la ley en su versión más auténtica, en tanto que original. Después de esa primera aparición, la igualdad ante la ley, en este mismo sentido material, ha ido ampliando su alcance, hasta significar que la ley no puede discriminar a las personas salvo por circunstancias relevantes, entre las que, en todo caso, no se encuentran la raza, el sexo, el nacimiento, la fe religiosa o las opiniones políticas. Así lo establece el transcrito art. 14 de la Constitución Española, bien es verdad que con un alcance aún más amplio, que deriva de su coletilla final.

En todo caso, tanto en su sentido original y más estrecho como en su sentido contemporáneo y más amplio, la igualdad ante la ley, en esta segunda acepción, no es más que una determinación sustantiva del valor de la justicia, es decir, una concepción de la justicia. Lo que supone es que, de cara a cómo deben ser tratadas, las personas no son desiguales por su pertenencia a un estamento o a un género o a una raza $y$, por tanto, sería injusto tratarlas, por alguno de estos motivos, de manera desigual. Por tanto, esta igualdad ante la ley no es sino la conclusión lógica que deriva de las dos premisas que antes he llamado igualdad axiológica (justicia) e igualdad fáctica. No debe, pues, ser considerada un valor independiente del de la justicia y parece ser la misma cosa que ese derecho a igual consideración y respeto del que habla DwORKIN.

Interesa recalcar el carácter sustantivo de esta versión de la igualdad ante la ley, porque a menudo ha sido calificada como igualdad «formal» y porque de esta calificación se ha derivado un desprecio injustificado por parte de cierto progresismo frívolo. La única igualdad ante la ley que podría ser calificada como «formal» sería, acaso, la igualdad en la aplicación de la ley, o igualdad lógica derivada de la misma idea de norma. En cambio, la prohibición de discriminación implicada por la igualdad en la ley justifica, o ha justificado, normas que han establecido la abolición de la esclavitud para las personas de raza no blanca, la posibilidad de acceso de los plebeyos a los cargos públicos de cualquier nivel, el ingreso de las mujeres en la universidad, la progresiva extensión del sufragio o el matrimonio entre personas de distinto sexo. Ninguna de estas normas establece una igualdad «formal» (un calificativo que, por cierto, resulta difícil de comprender, por lo menos en este contexto), sino sustantiva, porque opera un cambio sustantivo en la posición social de los afectados por la norma, en sus condiciones de vida.

Otra cuestión distinta es que cualquiera de estos cambios operados a través de la igualdad ante la ley se considere insuficiente de cara a la consecución de ciertos objetivos. Que se libere a los negros de la esclavitud puede considerarse insuficiente si siguen ocupando una posición subordinada en la pirámide social. Que los plebeyos tengamos acceso a los cargos públicos puede considerarse insuficiente si la mayoría de esos cargos siguen ocupados por aristócratas. O que las mujeres tengan derecho a ingresar en la universidad será insuficiente si no ingresan en una determinada propor-

43 KanT, 1993: 30-31. 
ción. Sin embargo, cada una de esas normas establece no sólo, como se dice, una igualdad meramente jurídica, sino una igualdad de hecho, aunque la igualdad de hecho que establece nos parezca demasiado corta. No es correcto tratar la igualdad de hecho y la igualdad de derecho como dicotómicas, porque toda igualdad de derecho conlleva alguna igualdad de hecho en la medida en que la norma jurídica correspondiente sea eficaz (es decir, se cumpla o se respete). El estatuto social de, digamos, una mujer plebeya y negra, es muy distinto, fácticamente distinto, si no puede ser sujeta a esclavitud, si puede ocupar un cargo público y si puede cursar estudios superiores, al caso contrario. Por eso, sorprende, y confunde, leer que las declaraciones clásicas de derechos (típicamente la francesa de 1789) establecieron sólo la igualdad formal o la igualdad jurídica, cuando en realidad supusieron un paso decisivo (aunque sólo un paso) hacia la igualdad sustantiva de las condiciones de vida de las personas. Mejor haremos en decir, con CASTORIADIS, que «estos derechos no han sido nunca formales (en el sentido de vacíos), sino que han sido siempre parciales, inacabados» ${ }^{44}$.

Llama la atención, por otra parte, el hecho de que, en una formulación del principio de igualdad ante la ley como la contenida en el Derecho constitucional español, el principio contiene dos exigencias bien distintas, hasta el punto de que, podríamos decir, una no exige nada y la otra lo exige todo. La igualdad en la aplicación de la ley podemos decir que no exige nada que no esté ya presente en la misma idea de «ley»o «norma», es decir, que se aplique sin consideraciones ajenas a las establecidas por la propia norma o, más sencillo, «que se aplique», porque cuando las normas se aplican teniendo en cuenta consideraciones que ellas no contemplan, las normas no se aplican correctamente, esto es, no se aplican. Por eso, un ordenamiento jurídico no requiere una norma específica que exija la igualdad en la aplicación de las normas, que va de suyo y, en este sentido, podemos decir que la norma que establece la igualdad en la aplicación de la ley «no exige nada».

En cambio, la igualdad en la ley, tal cual aparece formulada en el art. 14 de la Constitución Española, «lo exige todo», es decir, exige nada más y nada menos la justicia de las normas. Porque no otra cosa que justicia de las normas es lo que significa que éstas no deban discriminar, no ya por razón de «nacimiento, raza, sexo, religión, opinión», sino tampoco por «cualquier otra condición o circunstancia personal o social». Por supuesto, el término «discriminación» que usa el art. 14 ha de entenderse en su significado más estricto, como «trato injusto» y no como «trato diferente», porque, por reducción al absurdo, si le adscribiéramos este segundo significado, resultaría que el precepto no autorizaría ninguna distinción normativa entre las personas, esto es, no permitiría legislar. Esto, por cierto, vale para la cláusula genérica final del precepto, pero también para las cláusulas concretas de no discriminación, porque, en realidad, el Tribunal Constitucional ha acabado por admitir que las personas sí pueden ser tratadas de manera distinta por razón del sexo o la raza, siempre que este trato distinto sea un trato justo o justificado (por ejemplo, una medida de discriminación inversa o acción positiva que trate de equiparar la posición social de las mujeres a la de los varones). Luego el art. 14 lo que prohíbe es cualquier trato injusto, y así conduce a nuestro sistema jurídico a un vigoroso y radical iusnaturalismo: toda norma injusta es, ipso facto, una norma inconstitucional o, lo que es lo mismo, toda norma injusta es inválida, no

${ }^{44}$ CAstoriadis, 2005: 90. 
es una norma. El correlato institucional de este curioso resultado es que el Tribunal Constitucional debería anular cualquier norma injusta dictada por el poder legislativo. Y con esta sujeción del segundo al primero desaparecería la política. Reinaría la justicia o, mejor dicho, el Tribunal Constitucional. Los más atrevidos sueños de los partidarios del neoconstitucionalismo quedarían superados por la realidad constitucional española, o por cualquiera otra que contenga una norma similar a nuestro art. 14.

Como ya puede imaginar el lector, ni el Tribunal Constitucional ni nuestros constitucionalistas han llegado a tamaña conclusión, y han tratado de evitarla mediante una interpretación restrictiva del art. 14. Pero ¿cabe acaso una interpretación restrictiva de dicho artículo que sea, al mismo tiempo, lo suficientemente precisa? Porque parece evidente que el art. 14 prohíbe las normas injustas, luego la lógica restricción del precepto podría seguir una de estas dos vías: o bien se limita su alcance a ciertas «causas» de injusticia (las establecidas de manera expresa: sexo, raza, etc.), o bien se limita su alcance a ciertos «niveles» de injusticia: serían inconstitucionales las normas «muy» injustas, o «extraordinariamente» o «evidentemente» injustas, pero no las que fueran sólo «un poco» o «discutiblemente» injustas. En el primer caso se hace caso omiso de la cláusula de cierre del artículo, o incluso del significado genérico que cabe atribuir a sus palabras iniciales («los españoles son iguales ante la ley»), lo que no parece muy respetuoso con el texto de la Constitución; en el segundo caso se formula un criterio impreciso donde los haya. Luego ninguna de las dos soluciones parece buena. Nuestro Tribunal Constitucional, que debía ser deferente con el legislador si no quería minar la base del sistema democrático, ha descartado expresamente la primera y optado por la segunda, recurriendo a expresiones eufemísticas como la de «justificación objetiva y razonable» aplicada a la norma cuya constitucionalidad se examina. Es decir, las normas que establecen un trato desigual para los ciudadanos que no se halle objetiva y razonablemente justificado por el legislador serán inconstitucionales. Pero, si no es de tono, chay alguna diferencia entre ese requerimiento y el más sencillo y directo de que las normas han de ser justas? ${ }^{45}$.

Hay otra vía a través de la que ha sido limitado el alcance del mandato de igualdad del art. 14 y, teniéndola en cuenta, cabría pensar que los dos párrafos anteriores contienen una evidente exageración. Según una jurisprudencia constante, ese mandato exige tratar igual lo igual, pero no exige tratar desigual lo desigual, aunque lo autorice $^{46}$. Es decir, prohíbe tratar desigual lo igual pero no prohíbe tratar igual lo desigual. Si esta interpretación es correcta, la equiparación de la igualdad en la ley con la justicia sustantiva no es pertinente, porque la igualdad en la ley exige sólo, por así decir, la mitad de la justicia, pero no toda ella; en la práctica, esto supone una drástica restricción del alcance del principio de la igualdad en la ley. Hemos visto también, más arriba, que RuIz MiguEL proponía este alcance del principio de igualdad en la

45 Hay una amplísima jurisprudencia y una no menos amplísima literatura que trata de responder a esta pregunta mediante el esclarecimiento de términos tales como «objetividad», «razonabilidad», «proporcionalidad», «adecuación», etc. Me limito a recomendar los trabajos ya citados de RUIZ MigUEL y GIMÉNEZ GLÜCK, así como el que se cita en la nota siguiente. Con carácter más general, AleXY, 1993: 384 y ss.

46 Las Sentencias del Tribunal Constitucional que he consultado son las 86/1985, 52/1987, 109/1988 y 48/1989. He tomado la referencia de Ruiz Miguel, 2002: 692. Por desgracia, ninguna de ellas contiene un argumento que justifique esta opción interpretativa, limitándose todas a reiterar la afirmación de que el art. 14 no exige el trato desigual de lo desigual, quizá porque el Tribunal lo considera obvio. 
ley como un ejemplo que muestra que los valores de la igualdad y de la justicia no son uno y el mismo.

La cuestión es si esta interpretación de la igualdad en la ley la podemos admitir. Desde un punto de vista lógico, parece no haber problemas en ella siempre que nuestro punto de partida sea la exigencia de «trato igual de lo igual», puesto que el trato igual de lo igual no compromete con el trato desigual de lo desigual. En efecto, si $\mathrm{X}$ e $\mathrm{Y}$ merecen un trato igual y $\mathrm{Z}$ merece un trato desigual, y si yo trato igual a $\mathrm{X}, \mathrm{Y}$ y $\mathrm{Z}$, resulta que he respetado el deber de tratar igual lo igual, aunque también haya tratado igualmente a Z, a pesar de no merecerlo. Sin embargo, bastaría sustituir «trato igual» por «trato proporcional» o por «trato proporcionalmente igual» para, ahora sí, detectar una inconsistencia lógica, pues tanto uno como otro requieren tratar desigual lo desigual tanto como tratar igual lo igual. Ahora bien, uno puede insistir en que el art. 14 exige trato igual y no trato proporcional; para determinar si esto tiene sentido, hay que preguntarse por el fundamento de la norma, la razón de ser del mandato que contiene. La respuesta no puede ser otra que ésta: la norma exige trato igual en el nombre de la justicia, porque ya hemos comprobado que la igualdad, como tal, no es moralmente valiosa, sino que sólo lo es cuando se trata de una igualdad justa. El trato igual de lo igual está justificado, pero lo está exactamente por la misma razón por la que lo está el trato desigual de lo desigual, es decir, por razón de la justicia que supone, de manera que, si asumimos como regla de comportamiento el trato igual de lo igual, no tenemos razón alguna para no asumir, del mismo modo, el trato desigual de lo desigual, porque su fundamento es el mismo o porque, como dice WeSTEN, el trato desigual de lo desigual es «correlativo» del trato igual de lo igual. Por consiguiente, parece que la norma contenida en el art. 14 debería interpretarse como exigiendo «igualdad proporcional» y no «igualdad» a secas, y de aquí se sigue que exigiría el trato desigual de lo desigual tanto como el trato igual de lo igual.

En definitiva, el trato igual de lo desigual supone un comportamiento incoherente con el trato igual de lo igual. Si esto es así, entonces no hay razón suficiente para limitar el alcance del mandato de igualdad del art. 14 sólo al trato igual de lo igual, porque, al aceptar su justificación axiológica, nos vemos obligados también al trato desigual de lo desigual. Y, dicho sea de paso, el principio constitucional de la igualdad en la ley no sería un buen ejemplo de la posibilidad de distinguir entre el valor de la igualdad y el valor de la justicia, sino más bien de lo contrario.

Teniendo en cuenta estas consideraciones, el resultado de la interpretación oficial del art. 14 no puede resultar satisfactorio. Lo menos que se puede decir al respecto es que «la propia labilidad de los confines de la definición arroja una imagen siempre relativa del principio de igualdad en la ley, porque relativos son los criterios que se emplean para detectar las desigualdades y su racionalidad ${ }^{47}$. También podría irse un poco más allá y concluir que una norma como la del art. 14 es una norma que, por exigir todo, lo cual es demasiado, acaba por no saberse cuánto exige, es decir, una norma que acaba por no tener un significado determinado ni racionalmente determinable; $\mathrm{y}$ cuando esto le sucede a una norma, podemos decir que ha dejado de ser una norma. No es de extrañar, porque el valor que se halla detrás de la igualdad en la ley no es otro

\footnotetext{
47 Rodríguez-PiÑERo y Fernández LóPeZ, 1986: 55-56.
} 
que el de la justicia en toda su amplitud y profundidad, es decir, la vara de medir la corrección de cualquier norma jurídica.

\section{LA IGUALDAD MATERIAL: DE BIENESTAR, RECURSOS U OPORTUNIDADES}

El análisis de la igualdad ante la ley ha debido mostrar ya que la dicotomía entre igualdad formal e igualdad material es inaceptable, al menos si por igualdad formal se entiende la igualdad en la ley, porque ésta no es sino una forma de expresar una igualdad que nada tiene de formal y sí de sustantiva o, como también se la suele llamar, material. En todo caso, el ideal de la igualdad material, sea como igualdad de bienestar, recursos u oportunidades, se ha postulado con reiteración como el valor que fundamenta de manera específica los derechos sociales, y merece la pena que le prestemos un poco más de atención. Las tres igualdades aludidas en el título de la sección son desde luego distintas, o pueden configurarse como distintas, dando lugar a distintas teorías de la justicia distributiva ${ }^{48}$; pero las tres pueden calificarse como variantes de la igualdad material. Lo que sigue vale para cualquiera de las tres, con lo que podemos tratarlas conjuntamente.

Lo principal ya está dicho: del mismo modo que la igualdad en la ley expresa un juicio sustantivo de justicia, así lo hace cualquier otra modalidad de la igualdad material. Postularla como valor significa afirmar que ciertos bienes sociales (o, si se quiere, ciertos niveles de bienestar, recursos u oportunidades) han de estar al alcance de todos los miembros de la comunidad en las mismas condiciones. Los partidarios de los derechos sociales, invocando la igualdad material, lo que propugnan es que todos los miembros de la comunidad puedan disfrutar de iguales niveles o cuotas de tales bienes, sea educación, asistencia, trabajo o cualquier otro. La razón que les asiste, de la que no dudo, es que una tal distribución igualitaria es justa; y la cuestión que tenemos que solventar es si para acreditar esa justicia es necesario recurrir al valor de la igualdad material.

A mi juicio, ese recurso no es necesario. Quizá la prueba más evidente es que los partidarios del valor de la igualdad material no creen que exija una atribución igual de cualquier cosa que se nos ocurra, de cualquier ventaja social disponible, sino sólo de ciertos bienes que son especialmente importantes porque muestran una especial conexión con la vida buena, que, para los humanos, y según las teorías de los derechos, es una vida libre. Es decir, los partidarios de la igualdad material la invocan para asegurar un igual reparto de los bienes que dan libertad. Esta conexión entre derechos sociales y libertad, desde luego, supone una concepción de la libertad distinta de la libertad negativa o libertad como no interferencia que es típica de cierto pensamiento liberal. Aquí no hay espacio para exponer las razones por las cuales esta concepción liberal de la libertad es inaceptable (espero hacerlo en otro momento). Habrá de bastar con dar por buena la intuición de que los bienes garantizados por los derechos sociales hacen a las personas más libres (la educación es un caso paradigmático de eso) y con reconocer que, en cualquier caso, la bondad del argumento de esta sección depende de que

\footnotetext{
${ }^{48}$ DwORKIN, 2000: 12 y ss.
} 
podamos justificar esta intuición con buenas razones. Aceptando esa conexión entre libertad y derechos sociales, el argumento a favor de los derechos sociales (que puede valer también para otras distribuciones igualitarias de bienestar, recursos u oportunidades) podría ser uno como éste:

i) La comunidad política debe ser justa.

ii) Los miembros de la comunidad política son iguales en su capacidad para la libertad, que es su cualidad más valiosa.

iii) Luego se debe promover por igual su capacidad para la libertad (porque es justo).

iv) Luego se les debe atribuir cualesquiera bienes necesarios para promover dicha capacidad.

v) La educación, la asistencia o el trabajo son necesarios para promover dicha capacidad.

vi) Luego la educación, la asistencia o el trabajo deben ser atribuidos a todos los miembros de la comunidad política.

En este argumento, o en cualquier otro similar que construyamos, los únicos valores requeridos son el de la justicia y el de la libertad. No se ve qué razón habría para recurrir a un supuesto valor de la igualdad (material en este caso). Puesto que la igualdad que se valora es la igualdad en el reparto de todo aquello que contribuye a nuestra libertad, debe ser obvio que la igualdad no se valora como tal. No se valora cualquier reparto igualitario, sino sólo el que permite el disfrute de la libertad por parte de todos, porque todos son capaces de ese disfrute. Luego se valora la libertad de la que podemos disfrutar y se valora la justicia de que todos podamos disfrutarla. La igualdad axiológica que aparece aquí es sólo la propia de la justicia: como todos somos igualmente capaces para la libertad, todos hemos de ser tratados igualmente al respecto, mediante la atribución a todos de los instrumentos necesarios para el desarrollo de esa capacidad.

En este contexto, a la hora de justificar la atribución de derechos sociales, las disputas podrían surgir acaso en torno a: 1) lo que ha de entenderse por vida libre, y 2) la necesidad de disponer de educación, asistencia y trabajo para llevar adelante una vida como ésa. Responder a estas dos preguntas es una tarea básica para cualquier intento de justificación de los derechos sociales, pero ahora lo que importa es darse cuenta que ni una ni otra involucran una discusión sobre el valor de la igualdad. La primera es una pregunta acerca de la libertad y tiene carácter normativo. La segunda es una pregunta acerca de qué bienes sociales son necesarios para la vida libre y trata sobre hechos e instrumentos, no sobre valores. Por eso, los partidarios de los derechos sociales no necesitan del valor de la igualdad para justificar su causa y, al no necesitarlo, la refuerzan, porque pueden alegar con razón que los derechos sociales sólo buscan realizar el mismo fin al que sirven los derechos liberales, el fin de la libertad. En cambio, por muchas vueltas que se le dé, el supuesto valor de la igualdad, como tal, es incapaz de ofrecer razones a favor de la importancia de la educación, la asistencia o el trabajo. Para el caso, tan igualitaria es una sociedad de instruidos como una de analfabetos. En este sentido trivial, sí cabe afirmar que los derechos sociales están vinculados con la igualdad, en el sentido de que igualan a sus titulares en su disfrute; pero esto puede decirse de cualquier otro derecho fundamental. Tan trivial 
resulta esta vinculación con la igualdad que también la presenta cualquier norma que niega un derecho, en tanto que iguala a todos en la imposibilidad de disfrutar de él. En cambio, lo que es correcto y significativo es vincular todos los derechos fundamentales con la libertad; y entonces lo que se requiere es saber de qué hablamos cuando hablamos de libertad, y si los derechos sociales son necesarios para asegurar la libertad de todos.

De hecho, cuando vemos ponderar el valor de la igualdad no es difícil encontrar debajo el valor de la libertad y el de su reparto justo. Un ejemplo clásico y característico es el de la descripción que hace TOCQUEVILLE de la democrática e igualitaria sociedad norteamericana del siglo XIX. Al comienzo de su libro, escribe: «ninguna cosa me sorprendió tanto como la igualdad de condiciones». Pero ¿en qué consiste esa igualdad de condiciones? A renglón seguido descubrimos que se refiere a las cuotas que corresponden a los hijos en la herencia de sus padres, a la instrucción primaria, al conocimiento, al bienestar, al ejercicio de una profesión, a los derechos políticos... de manera que:

«América presenta, en su estado social, el más extraño fenómeno. Allí los hombres son más iguales en fortuna e inteligencia, esto es, más igualmente fuertes de lo que lo son en cualquier otro país del mundo» ${ }^{49}$.

El viajero francés seguirá observando, a lo largo de su relato, otras condiciones sociales que considera igualadas, pero ya podemos comprender que sus referencias constantes a la igualdad lo son, casi siempre, a la igualdad en ciertos aspectos de la vida que son condiciones para llevar una vida más libre. Esto es, la igualdad de condiciones que pondera al principio no es sino igualdad de condiciones para la libertad, por mucho que él no lo señale expresamente o que, como sospecha CASTORIADIS, no lo acabe de ver con claridad ${ }^{50}$. Es cierto que aquí no acaba el igualitarismo americano que observa TOCQUEVILLE, porque afecta también a determinados rasgos de la vida de los que podríamos afirmar que no favorecen la libertad o incluso que la perjudican. Pero, por la misma razón, tampoco encontraremos razones para valorar esa igualación. De modo similar, en el libro que dedicó a la Revolución Francesa, donde califica a la igualdad como una de las pasiones que la impulsaron, escribe también:

«Todos los hombres situados por encima del pueblo, en el fondo, se parecían: tenían las mismas ideas, los mismos hábitos, los mismos gustos, se entregaban a los mismos placeres, leían los mismos libros, hablaban el mismo lenguaje. Ya sólo se diferenciaban entre sí por los derechos» ${ }^{51}$.

Es decir, se diferenciaban en el grado de libertad de que disponían porque esos derechos han de ser considerados como cuotas de libertad adicionales a las que ya disfrutaban igualmente (placeres, libros...) y que tenían que ver con la expresión de las ideas, la protección frente a detenciones arbitrarias, el acceso a los cargos y empleos públicos o la participación en el poder político. En este sentido, la pasión igualitaria era la pasión por la libertad, aunque fuese por una libertad ejercida uniformemente (los mismos placeres, los mismos libros).

\footnotetext{
49 Tocqueville, 2002: Primera parte: Introducción y capítulo III.

50 CASTORIADIS, 2005: 92.

51 ToCQueville, 1982: 122.
} 
En cambio, cuando la igualdad se contrapone con la libertad, es difícil comprender de qué se está hablando. Una instancia clásica es la del famoso ensayo de I. BERLIN sobre los dos conceptos de libertad, en el que escribe:

«El alcance de la libertad de un hombre, o de un pueblo, para elegir vivir como él quiera, debe ser ponderado contra las pretensiones de muchos otros valores, de los cuales la igualdad, o la justicia, o la seguridad, o el orden público son quizá los ejemplos más obvios» ${ }^{52}$.

Confieso que no entiendo en qué sentido el valor de la libertad puede ser ponderado con el presunto valor de la igualdad (ni tampoco con el de la justicia). Más bien parece que la libertad de unos ha de ser ponderada con la libertad de otros o que ciertas libertades, o aspectos de la libertad, pueden menoscabar otras libertades u otros aspectos de la libertad. Se me objetará quizá que no he tenido en cuenta el sentido en que BERLIN maneja el concepto de libertad, como libertad negativa, que es a la que parece referirse en el pasaje transcrito. Sin embargo, la cuestión no es el tipo de libertad que se opone a la igualdad, sino el hecho mismo de oponer cualquier tipo de libertad a la igualdad. Pues si la libertad, negativa o de otro tipo, ha de ser un ideal, valor o bien comunitario, habría que esperar que estuviese repartida igualitariamente entre todos los ciudadanos. Suponiendo que BERLIN esté proponiendo este reparto igualitario de la libertad negativa, ¿a qué igualdad se refiere cuando la contrapone a ese reparto? Quizá a la igualdad respecto de algo valioso que no es la libertad negativa; pero, en este caso, el valor que se opone a la libertad negativa es ese algo valioso y no la igualdad en su reparto. Lleva razón A. SEN cuando afirma que quienes plantean la dicotomía igualdad-libertad incurren en un «error categórico», pues:

«[La libertad y la igualdad] no son alternativas. La libertad se encuentra entre los posibles campos de aplicación de la igualdad y la igualdad se halla entre los posibles esquemas distributivos de la libertad» ${ }^{53}$.

\section{EL PORQUÉ DE LA IGUALDAD}

Si el argumento que hemos venido siguiendo hasta aquí es correcto, habrá que convenir en la conclusión de que el valor de la igualdad no es necesario para formular una teoría de los derechos que corresponden a todas las personas. No permite justificar derechos ni tampoco constituye una razón a favor de uno u otro esquema de distribución de la riqueza, el bienestar, los recursos o las oportunidades sociales. Sin embargo, de aquí no se sigue que las demandas hechas en el nombre de la igualdad carezcan de fundamento. Muy al contrario, suelen tenerlo y suele ser fuerte, pero ese fundamento no puede radicar en la igualdad sino en otro valor o valores, o en una mezcla de consideraciones fácticas y valorativas. Aclarar cuál es el auténtico fundamento de las demandas igualitarias las hará más comprensibles, más sólidas y más atractivas. Éste es el caso de los derechos sociales, una de las demandas igualitarias más reiteradas de nuestra época, que podrán ser mejor fundados cuando se apoyen en la justicia, en la libertad y en ciertas características fácticas de los seres humanos.

\footnotetext{
52 BERLIN, 1986: 170.

53 SEN, 2004: 35.
} 
Antes de concluir, conviene hacerse una pregunta. Si la igualdad no parece ser un valor, si no puede fundamentar propuestas normativas, ¿cómo es que se ha constituido en uno de los grandes estandartes del progreso político, sobre todo durante la era moderna? A mi juicio, la respuesta es ésta: porque mediante el recurso a la idea de igualdad se ponía y se pone de relieve la contradicción entre el esquema dominante de legitimación política y su realización práctica. Los elementos clave de ese esquema son los tres que acabo de mencionar: justicia, libertad y básica igualdad de los seres humanos en su capacidad para la libertad. Según este esquema, una comunidad política justa ha de ser aquella que garantice una vida libre para todos sus miembros, porque una vida libre es el ideal humano por excelencia, y porque ese ideal, en tanto que humano, ha de estar al alcance de todos y no sólo de algunos.

Ahora bien, en la práctica este canon de legitimidad política se ha realizado de manera muy deficiente, porque no se ha garantizado la libertad de todos, sino sólo la de algunos, o la de unos en mayor medida que la de otros; y, diría, apuntar a esta contradicción entre el ideal y la realidad ha sido el motor del avance político durante los tres últimos siglos, si no incluso desde los tiempos de la Baja Edad Media, como observó TOCQueviLLE en la Introducción a su Democracia en América. La igualdad, que es el impulso al que se refiere de forma explícita TOCQUEVILLE, expresa precisamente esa discrepancia, porque de los tres elementos constitutivos de la legitimidad política nadie duda. No se duda del valor de la justicia ni del de la libertad, tampoco de que los seres humanos son básicamente iguales, y capaces todos ellos de ser libres. Por eso, recurrir a cualquiera de los tres como argumento a favor del cambio o del progreso social podría parecer inútil o insuficiente, porque los partidarios del orden establecido siempre podrían responder que ellos también se sienten vinculados por esos ideales y que los encuentran ya realizados en ese orden. En cambio, el recurso a la igualdad pretende mostrar que no hay tal consistencia entre lo que es y lo que debe ser, porque los ciudadanos de una comunidad política, siendo igualmente capaces para la libertad, no son igualmente libres; porque, siendo iguales, no son tratados igual, es decir, son tratados injustamente. El ideal de la justicia nunca ha sido negado; el de la libertad, pocas veces. Y, aun así, ni la justicia ni la libertad reinan sobre la tierra. El recurso al supuesto valor de la igualdad expresa esto.

En particular, el hecho ya comprobado de que se llame igualdad a la justicia tiene una clara razón de ser: la justicia exige el trato igual para los iguales y desigual para los desiguales, pero es el primero el que más se echa de menos. Si imaginamos una comunidad regida perfectamente por la justicia, habremos de imaginar una comunidad que presente un cierto nivel de trato desigual, ni más ni menos que el que expresa el concepto de la justicia, esto es, el que corresponda a la desigualdad relevante entre sus miembros. La comunidad, en cambio, sería injusta si ese nivel de trato desigual fuese mayor o menor, si hubiese un exceso de igualdad o de desigualdad. Sin embargo, las comunidades humanas reales siempre han sido más desiguales de la cuenta y no al contrario, es decir, la razón de ser de su injusticia es casi siempre la misma: su excesiva desigualdad y no su excesiva igualdad. Lo pueden acreditar las mujeres, las personas de razas no blancas, los inmigrantes, los trabajadores, los pobres. Todos ellos, cuando claman por la justicia, claman al mismo tiempo por la igualdad, porque es trato igual lo que falta, porque sobra trato desigual. Por tanto, y sobre todo en el plano de la ordenación política general, el que exige justicia casi siempre exige igualdad, porque la 
realidad jurídica y política, tal cual es, para ser justa requiere ser más igualitaria y no menos. Así es como deben leerse las proclamas igualitaristas, de las que el Manifiesto de los Iguales no es mal ejemplo:

«Siempre y por todos sitios se alimenta a los hombres con bellas palabras. Nunca y en ninguna parte han obtenido la cosa junto con la palabra. Desde tiempos inmemoriales se nos repite con hipocresía: los hombres son iguales, y desde tiempos inmemoriales la tan envilecedora como monstruosa desigualdad pesa insolentemente sobre el género humano» ${ }^{54}$.

Las cosas podrían ser al revés, y el mundo ser excesivamente igualitario para ser justo, pero cargamos con un largo pasado aristocrático que lastra el presente con un exceso de desigualdad. Luego no resulta extraño llamar «igualdad» a la justicia porque, de hecho, la exigencia de la segunda es la exigencia de la primera. En este sentido, es decir, en un sentido histórico, sí es cierto que los derechos sociales están vinculados con la igualdad, en el sentido de que su reconocimiento ha ayudado a extender la igualdad de condiciones entre los ciudadanos, pero del mismo modo que los demás derechos fundamentales, en su momento, también la extendieron.

La imagen de la justicia política no es la de un desigual igualmente tratado que reclama el trato desigual que en justicia le corresponde. La imagen, al contrario, es la de ese negro encadenado que figura en el medallón diseñado hacia 1787 por J. WEDGWOOD, el abuelo materno de DARWIN, para la inglesa Sociedad para la abolición del comercio de esclavos. Debajo de su imagen se encuentran estas palabras: «Am I not a Man and a Brother?». Y como ésta son casi todas las demandas de la justicia política: ¿No soy yo igual que tú? ¿Por qué, entonces, soy tratado peor que tú? No es extraño, insisto, que se formulen en el nombre de la igualdad ${ }^{55}$.

Al mismo tiempo que justicia, la demanda igualitaria incluye una petición de libertad. En el caso del medallón de WEDGWOOD, la libertad no se menciona, tampoco la igualdad ciertamente, pero las preguntas apuntan primero a la igualdad y no a la libertad. ¿No soy un Hombre (igual que tú, hombre blanco) y un Hermano (un hermano tuyo, un igual)? Eso sí, detrás de las respuestas afirmativas está esperando la libertad, pues, si soy un igual, ¿no he de ser igualmente libre como tú? ¿No es justo que lo sea? El lema del medallón, pues, explica bien de qué modo la demanda de igualdad resume los tres elementos de la legitimidad a los que vengo haciendo referencia: el hecho de la igualdad radical de los seres humanos, que son, por eso, hermanos; el valor de la justicia que, como iguales que son los seres humanos, requiere tratarlos igualmente; y el valor de la libertad que, como capaces que somos de ella, requiere que se nos atribuya. Quítese al hombre negro, y póngase a la mujer, o al pobre, o al emigrante: la demanda, ahora dirigida al varón, o al rico, o al ciudadano, sigue conservando su razón y su fuerza.

No es, por tanto, extraño que la igualdad se haya constituido en gran reivindicación política de nuestra era. Eso sí, cuando el pueblo la reclama es la libertad quien le guía, bajo el ojo atento de la justicia, que, contra lo que se suele creer, nunca ha sido ciega.

54 BabeUf y MARECHAL, 1993: 251.

55 Agradezco a V. MÉnDEZ BAIgES que me informase de la existencia del medallón de WEDGWOOD, y también sus muchos otros comentarios y sugerencias sobre este escrito. 


\section{BIBLIOGRAFÍA}

AleXy, 1993: Teoría de los derechos fundamentales, Madrid, Centro de Estudios Constitucionales.

Allan, T. R. S., 2001: Constitutional Justice. A Liberal Theory of the Rule of Law, Oxford University Press.

Arcos, F., 2001: La seguridad jurídica: una teoría formal, Madrid, Dykinson.

ARISTÓTELES, 1985: Ética nicomáquea, Madrid, Gredos.

- 1997: Política, Madrid, Altaya.

Babeuf, C., y Marechal, S., 1993: «Manifiesto de los Iguales», en V. Méndez Baiges (ed.), El discurso revolucionario, Barcelona, Sendai.

BerLIN, I., 1986: «Two Concepts of Liberty», en Four Essays on Liberty, Oxford University Press.

BobBiO, N., 1993: Igualdad y libertad, Barcelona, Paidós.

Calabresi, G., 1991: «Antidiscrimination and Constitutional Accountability (What the BorkBrennan Debate Ignores)», en Harvard Law Review, núm. 105.

CAMPBell, T., 2002: La justicia. Los principales debates contemporáneos, Barcelona, Gedisa.

Castoriadis, C., 2005: Escritos políticos, Madrid, Los Libros de la Catarata.

De LoRA, P., 2006: Memoria y frontera: el desafío de los derechos bumanos, Madrid, Alianza.

De LuCAS, J., 1996: «La igualdad ante la ley», en E. GARZÓN VALdÉs y F. LAPORTA (eds.), El Derecho y la justicia, Madrid, Trotta.

DíEZ-Picazo, L. M.: Sistema de derechos fundamentales, Cizur Menor, Civitas.

DwOrkin, R., 1978: Taking Rights Seriously, London, Duckworth.

- 2000: Sovereign Virtue: The Theory and Practice of Equality, Cambridge, Harvard University Press.

EsCudero, R., 2000: Positivismo y moral interna del Derecho, Madrid, Centro de Estudios Constitucionales.

FERRERES, V., 2009: «Sobre la posible fuerza vinculante de la jurisprudencia», en V. FERRERES y J. A. XIOL, El carácter vinculante de la jurisprudencia, Madrid, Fundación Coloquio Jurídico Europeo.

FINNIS, J., 1980: Natural Law and Natural Rights, Oxford, Clarendon Press.

Fuller, L. L., 1969: The Morality of Law, New Haven, Yale University Press.

GARCía MAnRique, R., 2003: «Acerca del valor moral de la seguridad jurídica», en Doxa, núm. 26.

- 2004: «¿Deben las mujeres tener derechos humanos específicos?», en Derechos bumanos e injusticias cotidianas, Bogotá, Externado de Colombia.

GARZÓN VALDÉS, E., 1993: «Seguridad jurídica y equidad», en Derecho, ética y política, Madrid, Centro de Estudios Constitucionales.

GiméNEz GLÜCK, D., 2004: Juicio de igualdad y Tribunal Constitucional, Barcelona, Bosch.

González Amuchastegui, J., 2004: Autonomía, dignidad y ciudadanía. Una teoría de los derechos bumanos, Valencia, Tirant lo Blanch.

Guibourg, R. A., 1996: «Igualdad y discriminación», en Doxa, núm. 19.

HaYeK, F., 1995: Camino de servidumbre, Madrid, Alianza.

Hart, H. L. A., 1980: El concepto de Derecho, Buenos Aires, Abeledo-Perrot.

Hierro, L. L., 2000: «¿Qué derechos tenemos?», en Doxa, núm. 23. 
— 2002: «El concepto de justicia y la teoría de los derechos», en E. Díaz y J. L. Colomer (eds.), Estado, justicia, derechos, Madrid, Alianza.

Hobbes, Th., 1980: Leviatán, México, Fondo de Cultura Económica.

KanT, I., 1993: Teoría y práctica, Madrid, Tecnos.

- 1996: Fundamentación de la metafísica de las costumbres, Madrid, Ariel.

Kelsen, H., 1991: ¿Qué es justicia?, Barcelona, Ariel.

LAPORTA, F., 1985: «El principio de igualdad: introducción a su análisis», en Sistema, núm. 67.

- 2002: «Imperio de la ley y seguridad jurídica», en E. DíAz y J. L. Colomer (eds.), Estado, justicia, derechos, Madrid, Alianza.

Lyons, D., 1993: «On Formal Justice», incluido en Moral Aspects of Legal Theory, Cambridge University Press.

Macklin, R., 2003: «Dignity is a Useless Concept», en British Medical Journal, núm. 327.

PINKER, S., 2008: «The Stupidity of Dignity. Conservative bioethics latest, most dangerous ploy», en The New Republic, 28 de mayo.

Radbruch, G., 1974: Introducción a la filosofía del Derecho, México, Fondo de Cultura Económica.

RaWLS, J., 1973: A Theory of Justice, Oxford University Press.

RAZ, J., 1986: The Morality of Freedom, Oxford, Clarendon Press.

RodríGUEZ-PiñERO, M., y FERNÁNDEZ LÓPEZ, M. F., 1986: Igualdad y discriminación, Madrid, Tecnos.

Ross, A., 1997: Sobre el Derecho y la justicia, Buenos Aires, Eudeba.

Ruiz Miguel, A., 1996: «La igualdad en la jurisprudencia del Tribunal Constitucional», en Doxa, núm. 19.

- 1997: «Equality Before the Law and Precedent», en Ratio Juris, núm. 10.

- 2002: «Concepto y concepciones de la igualdad», en V. ZAPATERO (ed.), Horizontes de la filosofía del Derecho, vol. 1, Alcalá de Henares, Servicio de Publicaciones de la Universidad.

Schauer, F., 1991: Playing by the Rules, Oxford, Clarendon Press.

SEN, A., 2004: Nuevo examen de la desigualdad, Madrid, Alianza.

SINGER, P., 1991: Ética práctica, Barcelona, Ariel.

Summers, R. S., 1993: «A Formal Theory of the Rule of Law», en Ratio Juris, núm. 6.

TocQueville, A., 1982: El Antiguo Régimen y la Revolución, Madrid, Alianza.

- 2002: La democracia en América, Madrid, Alianza.

WeInRIB, E. J., 1995: The Idea of Private Law, Harvard University Press.

Westen, P., 1982: «The Empty Idea of Equality», en Harvard Law Review, núm. 95.

- 2000: Speaking of Equality. An Analysis of the Rhetorical Force of «Equality» in Moral and Legal Discourse, Princeton University Press. 